\title{
Modelos delincuenciales y narrativas mediáticas sobre el delito. Los diarios argentinos Clarín y Crónica durante el período 1976-1979
}

\author{
María Paula Gago \\ CONICET-Universidad de Buenos Aires. Instituto de \\ Investigaciones Gino Germani. Buenos Aires.
}

mariapaulagago@gmail.com

Recibido: 26 de junio de 2017. Aceptado: 18 de octubre de 2017.

\section{Resumen}

En el presente artículo se retoman aspectos parciales de un conjunto de problemáticas abordados en un estudio precedente, sobre los modos de construcción de la noticia policial en la prensa gráfica durante la última dictadura cívico militar ocurrida en Argentina (1976-1983). Y su objetivo es exponer y explicar qué modelos delincuenciales y también qué núcleos argumentativos desarrollaron, durante el período 1976-1979, dos diarios argentinos de circulación nacional -Clarín y Crónica- en torno a los métodos represivos y de control social absolutos practicados en ese entonces. Los resultados obtenidos muestran que en la superficie redaccional de los medios estudiados coexistían tres modelos delincuenciales, en función de los cuales se desarrollaron dos narrativas opuestas pero complementarias, que resultaban favorables a una vigilancia estricta.

Palabras clave: Argentina; dictadura; prensa periódica; delincuencia; control social.

\section{Criminal models and media narratives about crime. Argentine newspapers Clarín and Crónica during the 1976-1979 period}

\begin{abstract}
This article reviews some of the issues tackled in a previous study, which looked at how crime news were constructed by the print press during the last civic-military dictatorship in Argentina (1976-1983). Focusing on the 1976-1979 period, our goal is to reveal and explain the criminal models and key arguments developed by two nationally circulated Argentine newspapers -Clarín and Crónica- in view of the methods of repression and absolute social control then in practice. Our results show that three criminal models coexisted on the pages of these newspapers, and that these models, in turn, led to the development of two opposing but complementary narratives that favored a context of strict vigilance.
\end{abstract}

Key words: Argentina, dictatorship, print press, crime, social control. 


\title{
Modelos criminais e narrativas mediáticas sobre o delito. Os jornais argentinos Clarín e Crónica durante o período 1976-1979
}

\begin{abstract}
Resumo
No presente artigo se retomam aspectos parciais de um conjunto de problemáticas abordadas em um estudo precedente, sobre os modos de construção da notícia policial na imprensa gráfica durante a última ditadura cívico-militar acontecida na Argentina (1976-1983). E seu objetivo é expor e explicar quais modelos criminais e que núcleos argumentativos foram desenvolvidos durante o período 1976-1979, por dois jornais argentinos de circulação nacional -Clarín e Crónica- ao redor dos métodos repressivos e de controle social praticados nesse momento. Os resultados obtidos mostram que na superfície redacional dos meios estudados coexistiam três modelos criminais, em função dos quais se desenvolveram duas narrativas opostas, mas complementárias, que resultavam favoráveis a uma vigilância estrita. Palavras chave: Argentina; ditadura; imprensa periódica; delinquência; crime; controle social.
\end{abstract}

\section{Introducción}

En los últimos años se ha avanzado considerablemente en el análisis de la última dictadura militar en la Argentina (1976-1983), tanto en el terreno económico, político y social, cuanto en el ámbito cultural. Las posibilidades de estudio van desde la evaluación política hasta el análisis del discurso, facilitando el desmontaje de los mecanismos de censura, ocultamiento y deformación en los que participaron los medios de prensa durante este período. Si bien se ha avanzado -entre muchos otros, Avellaneda, 1986; Gociol e Invernizzi, 2002; Sidicaro, 1996; Blaustein y Zubieta, 1999; Díaz, 2002; Mochkofsky, 2004; Muraro, 1987; Ulanovsky, 2005; Borrelli, 2008a, Borrelli, 2008b, Borrelli, 2016; Saborido y Borrelli, 2011; Schindel, 2012; Vitale, 2015- aún existen áreas que requieren estudios sistemáticos. El caso de la información policial en la prensa gráfica es uno de ellos.

En este trabajo ${ }^{1}$ proponemos analizar los modelos delincuenciales delineados en el discurso de la prensa y los núcleos argumentativos desarrollados en dos diarios argentinos de circulación nacional -Clarín y Crónica- tanto en los espacios editoriales cuanto en aquellos destinados a la información policial, en relación con la vigilancia y los métodos represivos y de control social absoluto practicados durante el periodo 1976-1979. Las hipótesis que lo guían son dos: 1) los medios estudiados apelaron a la retórica de lo delictivo para referirse no solo a los delitos comunes sino también a la subversión política y a hechos de protesta social como un tipo particular de delito. La utilización de esa retórica propia del género policial sustrajo la discusión sobre este fenómeno (la subversión) del ámbito político para reducirlo a una cuestión de tipo policial o de seguridad; en virtud de los modelos delincuenciales construidos en el

\footnotetext{
En este artículo retomamos parcialmente un conjunto de problemáticas abordadas en la tesis doctoral (Gago, 2015). Esta versó sobre los modos de construcción de la noticia policial en seis diarios de circulación nacional: La Nación, La Prensa, La Razón, Diario Popular, Crónica y Clarín.
} 
discurso de la prensa se organizaron narrativas favorables a la mano dura, las cuales -aunque con variaciones- siguen presentes en los relatos sobre la inseguridad.

En lo que respecta al corpus, está conformado por dos diarios, seleccionados por su circulación nacional y su ámbito de influencia. Los medios que analizamos se proponían a sí mismos como formadores de opinión pública, y sus posicionamientos presumiblemente tenían incidencia en los ámbitos decisorios. Además, como cada medio construye un contrato de lectura que apunta a un tipo de público específico, consideramos que esto dotó al trabajo de una mayor exhaustividad para explorar y analizar continuidades o variaciones en los núcleos argumentativos desarrollados por la prensa "seria" y la prensa amarilla (Steimberg, 1987) en torno al delito y al control social basado en el terror. De acuerdo con esa tipología, incluimos a Clarín en el primer grupo mientras que a Crónica lo ubicamos en el segundo². Por último, la escasa oferta informativa de radio y televisión de la época -manejada directamente por las Fuerzas Armadas- daba aun mayor relevancia al rol de prensa "independiente" (Borrat, 1989) como medio informativo y formador de opinión (Borrelli, 2008b).

Desde nuestro marco conceptual, consideramos a los medios como actores políticos (Borrat, 1989) y agentes privilegiados de producción y circulación discursiva que, con su accionar, por supuesto condicionado por su posición ideológica y por sus intereses empresariales, contribuyen a la conformación y modificación de los marcos de referencia -histórica y socialmente construidos- a través de los cuales las sociedades se piensan a sí mismas, elaboran sus experiencias pasadas y establecen para sí horizontes de futuros posibles.

En relación con la noticia policial, partimos de investigaciones previas (Saítta, 1998; Caimari, 2007, 2012; Martini y Pereyra, 2009) que la conciben implícita o explícitamente como una noticia política porque es un relato que reclama acciones del Estado, de la Justicia, mecanismos de control social, entre otros. En consonancia con lo mencionado, consideramos atinado recuperar la categoría de Josefina Ludmer (1999) de delito como un instrumento crítico y cambiante y por eso histórico. Esa decisión es la que nos permitió pensar cómo funciona ese instrumento crítico -el delito- en las crónicas periodísticas, en un contexto de carácter excepcional's: la última dictadura ocurrida en la Argentina (1976-1983).

\footnotetext{
Tal como señala Steimberg (2000) el término "prensa blanca o seria" se utilizaba para referirse a aquellos medios que no eran "amarillistas" básicamente por no mentir, aunque muchos pensaban que debería haber sido al revés: "que un diario era serio porque, mintiendo o diciendo la verdad, mantenía un cierto modo de no tomarse las cosas a lo chacota" (2000, pp. 237-38).

3 La excepcionalidad reside, siguiendo a Bobbio et al. (2005) en la suspensión de las garantías constitucionales y la instauración de facto que establece la ley marcial y el estado de sitio como fundamentos del orden social; el trastorno del orden político preexistente, movilizando a una parte de la sociedad y sometiendo con violencia a la oposición política; la instauración de un poder que no sufre límites jurídicos y carece de reglas claras para su propia sucesión, y la legitimación de ese orden de facto mediante un nuevo marco legal.
} 
A los efectos de realizar este trabajo, se utilizaron herramientas provenientes del Análisis Crítico del Discurso, sobre las cuales nos detendremos en el siguiente apartado. Finalmente, es oportuno señalar que como no todos los diarios contaban con una sección policial, se tuvieron en cuenta artículos que presentaran alusiones o argumentaciones en relación con la vigilancia y los métodos represivos y de control social absoluto practicados durante el periodo 1976-1979. En vínculo con lo anterior, conviene destacar que los diarios que contaban con varias secciones incluían a las noticias sobre la delincuencia subversiva en Sección Política (como hacía Clarín) o Información General (en el caso de Diario Popular, que no tomamos en consideración para este trabajo).

\section{Metodología y materiales}

El análisis discursivo propuesto en este trabajo se centrará en las condiciones de producción de cada uno de los diarios. Según plantea Van Dijk (1990) -pionero desde los años 80, junto a otros investigadores, en el Análisis Crítico del Discurso (ACD), que es una escuela particular dentro del análisis discursivo- en su trabajo dedicado a estudiar la noticia como discurso, el análisis del discurso es una disciplina interdisciplinaria. Se interesa por el análisis de los diferentes contextos del discurso, es decir, por los procesos cognitivos de la producción y la recepción, y por las dimensiones socioculturales del uso del lenguaje y la comunicación (Van Dijk, 1990). La tarea del analista reside en estudiar las relaciones complejas entre el texto y el contexto. El objetivo del análisis discursivo es producir descripciones explícitas y sistemáticas, que cuentan con las dos dimensiones mencionadas: textual y contextual. Siguiendo a Van Dijk (1990), las dimensiones textuales dan cuenta de las estructuras del discurso en diferentes niveles de descripción. Las dimensiones contextuales relacionan estas descripciones estructurales con diferentes propiedades del contexto, como los procesos cognitivos y las representaciones o factores socioculturales (Van Dijk, 1990).

La descripción de los contextos cognitivo y social se realiza detallando las relaciones sistemáticas entre texto y contexto para saber cuál es la influencia de los procesos cognitivos, en producción y reconocimiento, de las estructuras del discurso y cómo estas influyen y son influidas por la situación social. La relación texto-contexto no se concibe como una oposición entre un texto, suponiendo una suerte de pre-existencia de un texto en formato "puro" opuesto a un contexto "externo". Al momento de las enunciaciones textuales se conjugan diversos textos que se entrelazan en un discurso en particular. En consecuencia, esta perspectiva no toma el discurso como una unidad autónoma que puede ser analizada de una forma inmanente. Puesto que el discurso está siempre sobredeterminado, condicionado y regulado por condiciones sociales de producción formadas por otros discursos y otras estructuras institucionales, econó- 
micas y políticas, la investigación se focalizará en las relaciones entre esas condiciones de producción y el proceso de producción discursiva. Esto nos llevará a establecer las condiciones históricas y sociales concretas en las que la enunciación fue producida (Verón, 1985).

Para abordar a los textos informativos nos basaremos en una serie de preguntas propuestas por Van Dijk (1997) con el objetivo de analizarlos de forma crítica, a saber:

- ¿Quiénes son los actores (protagonistas y secundarios) de las noticias?

- ¿Quiénes son los actores activos (agentes) y quiénes los participantes pasivos

- (pacientes)?

- ¿Qué acciones se subrayan, se describen o se ignoran?

- ¿Qué fuentes se citan y cómo se legitiman?

- ¿A quién se cita (o no) y con qué formulación estilística?

A su vez para el estudio de los discursos periodísticos y su construcción tendremos en cuenta conceptos fundamentales de la teoría de la noticia ${ }^{4}$ : consideración de las rutinas periodísticas, como formas de organización del trabajo en los medios, viabilizadoras de una concepción de mundo; jerarquización y estructuración de agendas temáticas y atributivas; la concepción de noticiabilidad que sostiene cada órgano mediático y el manejo de criterios que posibilitan el pasaje del acontecimiento, ruptura en la cotidianidad, a la noticia; las modalidades discursivas o de enunciación específicas -vinculadas al contrato de lectura (Verón, 1985) - y las atinentes al diseño de las unidades informativas y la relación con las fuentes (Wolf, 1991; McCombs y Shaw, citados en Martini y Gobbi, 1998; Mar de Fontcuberta, citada en Ruiz y Albertini, 2008).

Es importante señalar que en nuestro estudio más allá de los criterios de "gravedad"/"ruptura de la cotidianeidad" y proximidad geográfica se suma sobre todo durante 1976-1978 otro relacionado de modo directo con la imposición de qué y cómo comunicar, acorde con la agenda política y los cánones discursivos del gobierno dictatorial.

En razón del discurso particular que proponemos analizar también se tendrán en cuenta aportes teóricos del género periodístico policial (Caimari, 2007, 2012; Saítta 1998) que permitirán identificar sus marcas en distintos momentos históricos como así también su inclusión en series culturales más amplias, a categorías vinculadas a las teorías del delito ${ }^{5}$ y el control social (Garland, 2005), que permitan analizar el corpus en clave de "relatos del orden" en un contexto dictatorial.

\footnotetext{
Según Martini (2000), la teoría de la noticia puede definirse como aquella que intenta dar cuenta de las diferentes formas y procesos de construcción de la información periodística.

5 Retomaremos algunas conceptualizaciones centrales de las teorías del underclass y del etiquetamiento (Kessler, 2004).
} 
Para este trabajo tomamos en consideración un caso perteneciente a la agenda política, el asesinato de Cesáreo Cardozo (1976), inscripto en la serie "delitos subversivos"; el caso policial de María de las Mercedes "Yiya" Murano (1979), circunscripto en la serie de "crímenes espectaculares" y, finalmente, unidades informativas de la agenda policial: el ladrón de cables de alta tensión y el ladrón de sábanas blancas y órganos electrónicos, ocurridos en el año 1976. Se acotó el corpus de análisis, y quedó conformado por 27 artículos en total, distribuidos de la siguiente manera:

Sobre el caso Cardozo: 5 artículos publicados en la sección Política de Clarín y 3 noticias de Crónica:

- "Rindieron póstumo homenaje al General Cardozo" (Clarín, 20/6/1976, pp. 2-3).

- "Signo de derrota" (Clarín, 20/6/1976, p. 3).

- "Estupor ante el bárbaro atentado" (Clarín, 20/6/1976, p. 4).

- “Continúa la búsqueda de Ana M. González" (Clarín, 22/6/1976, p. 4). "Designarán hoy al jefe de Policía" (Clarín, 22/6/1976, p. 3).

- “Asesinan al Jefe de la Policía Federal” (Crónica, 18/6/1976, Tapa y pp. 8-9).

- "Inhuman a Cardozo" (Crónica, 19/6/1976, Tapa y pp. 8 y 9).

- "La asesina y su familia fugaron" (Crónica, 19/6/1976, p. 9).

Sobre el caso Murano: 5 crónicas publicadas en la sección Policía de Clarín y 10 en Crónica entre el 23 de mayo y el 30 de mayo de $1979^{6}$ :

- "Tres crímenes confirmados y otros dos posibles. El cianuro hizo su obra" (Clarín, 23/5/79, pp. 36-37).

- "Ascienden a siete las víctimas de la envenenadora" (Clarín, 24/5/79, pp. 38-39).

- "Conmueve el caso de la envenenadora" (Clarín, 25/5/79, p. 23).

- "Una semana clave en torno a los asesinatos con cianuro" (Clarín, 26/5/1979, p. 22).

- "Ante un vallado de silencio" (Clarín, 29/5/1979, p. 32-33).

- “¿Buenos Aires ante el estupor más horroroso? Mujer asesinó a 5 prestamistas" (Crónica, 23/5/1979, Tapa).

- “Demoníaco exterminio" (Crónica, 23/5/1979, pp. 10-11).

- "Habla el marido" (Crónica, 23/5/1979, p. 11).

- "Crónica revela detalles aterradores del episodio que conmociona al país. Serían 7 las víctimas de la diabólica envenenadora" (Crónica, 24/5/1979, Tapa y pp. 8-9).

- "Elegante y timadora, derrochaba fuertes sumas" (Crónica, 24/5/1979, p. 8).

- "No mataba una mosca, afirma el azorado portero" (Crónica, 24/5/1979, p. 8).

- "Envenenadora: ¿complicidad de 2 médicos?" (Crónica, 25/5/1979, Tapa).

- “Para meditarlo ¿cómo consiguió el cianuro?” (Crónica, 25/5/1979, p. 8).

6 La mayor cobertura otorgada por Crónica en ese lapso se explica por el contrato de lectura del matutino y por el rédito que le supone la cobertura de este tipo de noticias. 
- “¿Ocho víctimas de la bienuda asesina?” (Crónica, 26/5/1979, pp. 5-6).

- "Envenenadora: los cómplices al caer" (Crónica, 27/5/1979, pp. 8-9).

Sobre el delito común: 4 unidades informativas, 2 publicadas en la sección Policía de Clarín y 2 en Crónica: dos de esos artículos se refieren al caso del ladrón de cables de alta tensión y los dos restantes se refieren al ladrón de sábanas blancas y órganos electrónicos.

- "Detuvieron en Burzaco a un ladrón de sábanas blancas" (Clarín, 1/8/1976, p. 20).

- "El colmo de un ladrón" (Clarín, 5/8/1976, p. 15).

- "Llevábase todo, hasta órganos" (Crónica, 1/8/1976, p. 6).

- "Intenta robar un cable y casi muere fulminado" (Crónica, 6/8/1976, p. 8).

\section{El golpe de Estado de 1976}

Hacia mediados de la década de los años 70 las Fuerzas Armadas establecieron la necesidad de poner en práctica una "revolución desde arriba" para llevar adelante una tarea "refundacional", que encontró apoyo en una coalición civil", y que estaría dirigida a los campos político, económico, cultural, educativo, entre otros (Borrelli, 2016; Canitrot, 1980; Cavarozzi, 2006; Novaro y Palermo, 2003; Canelo, 2009, 2016; Vázquez, 1985).

Aunque las desapariciones de personas habían comenzado en 1974 de la mano de la Alianza Anticomunista Argentina (Triple A), en 1976 los militares sostenían ${ }^{8}$ que

\footnotetext{
Si bien el golpe de Estado fue ejecutado por las Fuerzas Armadas, contó con el apoyo de una coalición cívica. La fracción cívica de la coalición estaba conformada por sectores económicos de la alta burguesía vinculada a las finanzas, la industria y la propiedad de la tierra, el capital extranjero y los empresarios nucleados en torno a la liberal Asamblea Permanente de Entidades Gremiales Empresarias (APEGE) -que habían realizado el lockout del 16 de febrero de 1976 contra el gobierno peronista- (Borrelli, 2016). Otro sector fundamental de la coalición fue la Iglesia Católica, que aportó apoyo espiritual y material (Novaro y Palermo, 2003). Por su parte, los partidos políticos prestaron su consenso - por acción u omisión- al encumbramiento de las Fuerzas Armadas como único actor capaz de asegurar el orden público en 1976 (Yannuzzi, 1996). La actividad política había sido suspendida por el Decreto 6 (Groisman, 2001) aunque no prohibida. De acuerdo con Novaro y Palermo (2003), y Borrelli (2016), desde la Secretaría General de la Presidencia, Villarreal y Yofre idearon estrategias de acercamiento entre civiles y militares que tuvieron varias expresiones; Jorge R. Videla participó de una serie de almuerzos mensuales con figuras representativas de diferentes ámbitos de la sociedad civil entre abril y septiembre de 1976: entre ellos, radicales, socialistas, demoprogresistas, comunistas, desarrollistas y partidos provinciales (Novaro y Palermo, 2003). Según Borrelli (2016), con los peronistas los contactos fueron más esporádicos; se mantuvieron intendentes civiles en las provincias y embajadores. Videla no confrontaba con los "duros", ya que no se convocaba a figuras de partidos políticos tradicionales ni sindicales, fuertemente estigmatizados luego de la debacle del proceso político iniciado en 1973 (Yannuzzi, 1996). En el caso del Partido Comunista Argentino, a partir del golpe de Estado de marzo de 1976, impulsó la política de "convergencia cívico-militar", para frenar el avance del fascismo o pinochetismo dentro de la Junta Militar (Casola, 2015). Sin embargo, a pesar de las prerrogativas obtenidas por el mantenimiento de la legalidad a nivel nacional en algunos lugares de militancia como, por ejemplo, Jujuy, padecieron de una intensa represión (Casola, 2015).

8 El discurso "de aniquilación de la subversión" del cual los militares se apropiaron hacia 1976 se verifica en las declaraciones que vertían ante los medios de prensa de la época. A modo de ejemplo, entre muchas otras, véase la nota titulada "La subversión ya no es una alternativa, afirmó Videla", (Clarín, 1/11/1976, p. 3).
} 
para cambiar la sociedad se debía aniquilar la guerrilla. La represión, puesta en práctica en Tucumán en 1975 bajo el denominado Operativo Independencia ${ }^{9}$, fue ejecutada de un modo sistemático en todo el país un año después.

Si bien la buena colaboración y la armonía entre las tres Fuerzas Armadas era indispensable para acometer el proyecto político militar, ya desde los preparativos del golpe no se había logrado precisar el plan político que aplicaría el autodenominado "Proceso" debido a la falta de acuerdo entre las fuerzas y en el interior del Ejército al respecto (Novaro y Palermo, 2003). Sin embargo, los equipos que prepararon la toma del poder dejaron la cuestión de lado para evitar un quiebre de la aparente comunión alcanzada entre las fuerzas.

Desde octubre de 1975 se gestó la coordinación represiva entre las dictaduras del Cono Sur, conocida como "Plan Cóndor". Esto significó la creación de una "oficina de coordinación y seguridad"-que funcionó en las décadas del 70 y el 80integrada por los servicios de inteligencia y organismos de seguridad de varios países sudamericanos con la finalidad de "enfrentar la acción de la guerrilla", utilizando métodos de represión que, mediante la aplicación de los decretos 261/75, $2770 / 75,2771 / 75$ y $2772 / 75^{10}$, ya se habían empleado en el mencionado Operativo Independencia.

En el caso argentino, la Junta Militar que tomó el poder el 24 de marzo de 1976 -integrada por el general Jorge Rafael Videla, el almirante Emilio Eduardo Massera y el brigadier Orlando Ramón Agosti-, se abocó a la edificación de un "orden nuevo" en el que se impusiera la "vigencia de los valores de la moral cristiana", supuestamente quebrantados. Su objetivo era doble: "encauzar" la economía y disciplinar a la sociedad (Acuña y Smulovitz, 1995; Canitrot, 1980).

Uno de los instrumentos principales del proyecto refundacional, fue el plan sistemático de secuestros masivos de opositores políticos en centros clandestinos de detención, posterior tortura, asesinato y desaparición en una vasta represión ilegal que produjo miles de desaparecidos.

La planificación general y la supervisión táctica estuvo en manos de las cúpulas castrenses, que habían tomado el poder estatal, pasando por la cadena de mandos, hasta los grupos de tareas que ejecutaban directamente las acciones criminales, poniendo de relieve el carácter institucional de la acción y el comportamiento.

Aunque esa conducción centralizada combinó una estructura operativa en gran medida informal y descentralizada, "permitió a los represores usufructuar las ventajas

\footnotetext{
Marín (1996) contabiliza, analiza y reflexiona sobre los hechos armados ocurridos entre 1973 y 1976 bajo el gobierno constitucional de Isabel Martínez de Perón. Sobre esta temática también se recomiendan Izaguirre et al. (2009), Artese y Roffinelli (2007).

${ }^{10}$ Los decretos pueden consultarse en http://constitucionweb.blogspot.com.ar/2009/12/los-decretos-deaniquilamiento-de-la.html.
} 
de la estatalidad, pero en un marco de autonomía operativa" (Novaro y Palermo, 2003, p. 118).

El terrorismo de Estado estuvo dirigido contra obreros, dirigentes políticos y sindicales opositores, miembros de las organizaciones político-armadas y militantes políticos de diversa índole (periodistas, estudiantes, trabajadores sociales, sacerdotes y sectores movilizados políticamente). También las operaciones clandestinas represivas fueron utilizadas como un recurso criminal para saldar disputas de poder inter e intra Fuerzas Armadas y alcanzó, aunque más excepcionalmente, a empresarios, parientes o amigos de las víctimas originales, entre otros (Borrelli, 2016). Además de las organizaciones guerrilleras, "el ámbito sindical y el educativo fueron prioritarios para la represión militar" (Novaro y Palermo, 2003, pp. 114117). La práctica represiva clandestina no solo tuvo como objetivo silenciar definitivamente a los opositores, sino además lograr un certero disciplinamiento social, profundizar la despolitización de la sociedad civil y desgarrar los lazos de solidaridad social que habían crecido en los años anteriores (Borrelli, 2016).

El período más cruento se desarrolló desde 1976 hasta mediados de 1978, momento a partir del cual paulatinamente se iría "desarmando la estructura represiva (aunque sin dejar de operar en lo inmediato)" (Borrelli, 2016, p. 41).

El "Proceso" supuso la coexistencia de un Estado terrorista clandestino, encargado de la represión, y otro visible, sujeto a normas establecidas por las propias autoridades que, si bien habían tomado ilegalmente el poder, sometían sus acciones a una cierta juricidad. Las instituciones del Estado fueron laxas y elásticas para llevar a cabo el exterminio y el avance de un proyecto favorable a las clases dominantes. De acuerdo con Borrelli (2016):

...la clandestinidad represiva se ocultaba, pero no se invisibilizaba totalmente, para expandir estratégicamente la ubicua sensación de miedo. De esta manera, el terror se instaló tanto en el ámbito público como en el privado, consolidando las actitudes de preservación y fractura de la solidaridad social (p. 48).

\section{Los medios de comunicación y la dictadura: una relación farragosa}

En los prolegómenos del golpe, los militares habían hecho circular una cartilla con las palabras que consideraban inadecuadas. "Una larga lista de términos prohibidos y aceptados por los dueños de las empresas periodísticas que la hicieron respetar. Una vez en el poder estas sugerencias iban a convertirse en normas" (Postolski y Marino, 2006, p. 5). 
Como es sabido, la Junta Militar que asumió en 1976 estableció su propio marco legal ${ }^{11}$. Y el mismo 24 de marzo publicó el Comunicado 19, en el que establecían: “[...] será reprimido con reclusión de hasta 10 años el que por cualquier medio difundiere, divulgara o propagara noticias, comunicados o imágenes, con el propósito de perturbar, perjudicar o desprestigiar la actividad de las fuerzas armadas, de seguridad o policiales".

En la madrugada del golpe, indican Postolski y Marino (2006), fueron convocados los directivos de los medios de comunicación metropolitanos a la sede del Comando General del Ejército. Allí se les informó la decisión de implantar un régimen de censura y les fue entregada una cartilla "para que faciliten la tarea del censor" (Postolski y Marino, 2006, p. 6). Además, se creó un "Servicio Gratuito de Lectura Previa" ${ }^{12}$ que funcionaba en el interior de la Casa Rosada, "donde debían enviarse un juego por triplicado de cada edición: una de esas copias era devuelta con las 'correcciones', y las otras dos, eran remitidas para 'el análisis de censura posterior"' (Postolski y Marino, 2006, p. 6). En cuanto a los medios gráficos, Borrelli (2016 ) y Díaz et al. (2004) indican que Videla convocó el 1 de abril de 1976 a los directivos de los más destacados diarios capitalinos a una reunión; encuentros que en adelante se llevarían a cabo con grupos reducidos de dos o tres periodistas (Díaz et al., 2004) ${ }^{13}$. En esa oportunidad, los directores de la prensa nacional y de las radios privadas que se reunieron con las más altas autoridades del gobierno militar, concertaron pautas de autocensura con la justificación de no "favorecer" a las organizaciones guerrilleras (Borrelli, 2016).

Entre otras medidas se allanaron empresas periodísticas, se detuvo, se encarceló y se desapareció a periodistas, pero, además:

...se intervino militarmente a la Federación Argentina de Trabajadores de la Prensa; se clausuró y/o prohibió la circulación de revistas y periódicos; se expulsó a corresponsales de agencias extranjeras de prensa y radio, y se quemaron numerosos libros y revistas [...]. En el área de la radiodifusión, todos los medios entraron en cadena y quedaron bajo la autoridad de la Secretaría de Prensa y Difusión (Postolski y Marino, 2006, pp. 5-6).

\footnotetext{
${ }^{11}$ Con respecto a los medios de prensa, el marco legal estaba conformado por la Ley 20.840 de "seguridad nacional" o "ley antisubversiva" y los posteriores decretos 1273/75, 2770 y 2771. Estos, en palabras de Díaz et al., "ofrecieron un marco jurídico apropiado para concretar las políticas comunicativas negativas y consolidar la primera etapa de sistematización del discurso censorio durante la democracia. El primer 'aporte procesista' llegaría poco tiempo después cuando en junio de 1976 se sancionara la Ley 21.322 -que proponía se extendiera su aplicación a todos aquellos medios que expresaran una posición 'totalitaria'; y con la sanción de la Ley 21.459 que ampliaba los alcances de su antecesora 20.840" (Díaz et al., 2004, p.11). El otro instrumento legal elaborado por los militares en relación con los medios de comunicación fue la Ley de Radiodifusión 22.285, sancionada en 1980.

${ }^{12}$ Los autores señalan que la aplicación de estas políticas tuvo diferentes grados de implementación. "De la dureza del primer momento se pasó a distintas instancias de negociación” (Postolski y Marino, 2006, p. 6). De este modo, el "Servicio Gratuito de Lectura Previa" dejó de funcionar al mes, y en los canales de televisión surgieron tácticas para sortear las prerrogativas de los asesores literarios, quienes se irían ablandando con los años.

${ }^{13} \mathrm{Al}$ primer encuentro concurrieron: Horacio Rioja y Héctor Magnetto (Clarín); Patricio Peralta Ramos (La Razón); Bartolomé Mitre y Bartolomé Mitre (La Nación); Alberto Gainza Paz y Máximo Gainza Castro (La Prensa); Jacobo Timerman (La Opinión); Luis Clur (La Tarde) y Héctor Ricardo García (Crónica) (Blaustein y Zubieta, 1999).
} 
El control de los servicios de radiodifusión había pasado a manos del Estado hacia 1973, a partir de pautas legales que habían sido modificadas durante el mandato del general Lanusse, que estableció que las licencias concedidas a los canales privados se contarían desde el día en que habían sido entregadas y no desde la fecha en que se habían iniciado las transmisiones. De esta manera la estructura de propiedad de los medios pasó a ser fundamentalmente estatal.

Cuando la dictadura militar llegó al poder se encontró con el monopolio de la televisión, que le permitió ejercer la censura de la información que recibía (Muraro, 1987). De este modo las emisoras de TV fueron manejadas por los interventores militares: Canal 13 pasó a manos de la Armada, Canal 11 a la Fuerza Aérea y Canal 9 fue adjudicado al Ejército ${ }^{14}$, y en 1984 -pese a que el resto de los medios se mantuvo en manos del Estado hasta la década del 90- fue devuelto a su antiguo dueño -el empresario teatral Alejandro Romay- tras un fallo de la justicia. Canal 7, Argentina Televisora Color (ATC) tuvo una dirección tripartita (Mestman, 1992; Muraro, 1987; Postolski y Marino, 2006).

La dictadura fue clara en su accionar frente a las empresas de prensa: los medios críticos fueron intervenidos o clausurados; "aquellos que quisieron mantener algún rasgo de autonomía frente a su accionar político eran reprimidos ${ }^{15}$, y aquellos que funcionaron como adictos fueron tratados con esmero. Se priorizó la relación con las empresas de prensa, y se contempló situaciones de privilegio para el sector" (Postolski y Marino, 2006, p. 8) ${ }^{16}$.

De acuerdo con Varela (2001):

...hubo dos momentos de "pico" en lo que se refiere a la difusión de la ideología del régimen, dados por el campeonato mundial de fútbol (junio y julio de 1978) y por la guerra de Malvinas (abril a junio de 1982); y una distinción muy clara entre una primera etapa de persecución y censura (1976-1980) y un segundo momento de quiebre del discurso monolítico dictatorial que se acentúa después de la derrota de Malvinas, anunciando la apertura democrática (p.51).

${ }_{14}$ Postolski y Marino señalan que, para contrarrestar la influencia de la Armada sobre los medios, el Ejército puso bajo su órbita a la Secretaría de Comunicaciones (SECOM) y al Comité Federal de Radiodifusión (COMFER). Este controlaba los medios estatales y privados, a través del registro de las emisiones de radio y televisión. La SECOM, dependiente del Ministerio de Economía, era el organismo rector en el campo de las comunicaciones. Tenía a su cargo la prestación del Servicio Oficial de Radiodifusión “(L.R.A. Radio Nacional y sus 40 filiales, y si bien ATC formaba parte del SOR, dependía directamente del Ejecutivo) y del Servicio de Radiodifusión Argentina al Exterior (R.A.E.), la administración y el control del espectro radioeléctrico, y participaba de los aspectos técnicos que se relacionaban con los servicios de radiodifusión sonora y televisión. Bajo su órbita estaba la Empresa Nacional de Telecomunicaciones" (2006, p. 7).

15 De acuerdo con un informe de la Unión de Trabajadores de Prensa de Buenos Aires (UTPBA) en los primeros tres meses de la dictadura hubo 87 periodistas desaparecidos: 45, en 1976; 31, en 1977, y 11, en 1978. La última desaparición data de 1980 y se trató del caso de una reportera norteamericana radicada en el país (Ulanovsky, 2005).

16 En relación con los privilegios que la dictadura "contempló" hacia el sector de medios de comunicación, Postolski y Marino marcan tres casos. En primer lugar, la negociación extrajudicial con los exlicenciatarios de los canales de TV, que implicó un altísimo costo al Estado; en segundo lugar, la incorporación de la norma Pal N para la emisión de señales cromáticas, que implicó "toda una reconversión tecnológica y adecuación técnica, que generó cuantiosas inversiones financiadas por el Estado, y en parte usufructuadas por los privados" (2006, p. 10). Y, por último, la transferencia de acciones -luego de ocurrida la extraña muerte de David Graiver hasta ese entonces propietario de la mayoría de las acciones de Papel Prensa- y la consecuente conformación de una sociedad entre los diarios La Nación, Clarín, La Razón y el Estado. (Sobre este tema pueden consultarse Díaz et al., 2009; Postolski y Marino, 2006; Ulanovsky, 2005; Borrelli, 2008; Llonto, 2003). 
Dentro de la primera etapa que señala la autora, la censura y la intervención del poder militar en el ámbito de lo cultural no operó de igual modo en los diferentes medios de comunicación. Por ejemplo, en la cinematografía o la radiodifusión la censura fue más clara y explícita. Hubo también un espacio que el ojo del censor vigiló con firmeza: "el de la literatura infantil. Los militares se sentían en la obligación moral de preservar a la niñez de aquellos libros que - a su entender- ponían en cuestión valores sagrados como la familia, la religión o la patria" (Invernizzi y Gociol, 2002, 110).

A diferencia de otros regímenes autoritarios, en la Argentina no existió una oficina de censura centralizada (Avellaneda, 1986), por lo tanto, los medios no funcionaron en "bloque" (Varela, 2001). Tal como indica Mangone (1996): "[...] la dictadura tuvo su política cultural y la de su clase que la sustentó, tuvo sus jóvenes y sus músicos (y su música), tuvo su teatro [...], tuvo a sus 'miembros del espectáculo', no se privó de sus intelectuales y de sus periodistas” (p. 39).

En este sentido, Borrelli (2016) apunta: "pese a su práctica censora, para el régimen militar la actividad periodística no debía silenciarse totalmente. Por el contrario, se toleraba una prensa 'tibia', que execrara de los 'subversivos', pero que a la vez juzgara con una crítica moderada al propio gobierno" (p. 87).

El 12 de mayo de 1976, luego de una reunión con 163 representantes de diarios del interior, Videla declaraba: "recalco la objetividad, porque lejos de nuestro ánimo y espíritu estaría pensar en tener una prensa complaciente y no objetiva" (Graham-Yooll, citado en Borrelli, 2016, p. 87).

Y si bien los estudios sobre el rol de la prensa durante el periodo dictatorial (Blaustein y Zubieta, 1999; Ulanovsky, 2005) indican que los discursos periodísticos funcionaban como soportes ideológicos del discurso autoritario, “[...] era posible conocer mínimamente la situación política a través de conversaciones o contactos personales y de publicaciones de circulación restringida que, en los últimos años del periodo, llegaron a ocupar un espacio importante entre la producción cultural" (Varela, 2001, p. 52).

\section{Las empresas editoras: breve historia de Clarín y Crónica}

\section{Clarín (1945)}

El primer ejemplar del diario Clarín salió a la calle el 28 de agosto de 1945 y fue fundado por Roberto Jorge Noble, un abogado, político ${ }^{17}$ y periodista argentino.

\footnotetext{
${ }_{17}$ Noble fue fundador del Socialismo Independiente (fracción a la que representó como diputado en 1928). Dio sus primeros pasos periodísticos en el diario La Vanguardia, y fue subdirector y luego director del periódico militante Libertad. También trabajó en la sección deportiva del diario La Nación, fue uno de los fundadores del semanario Crítica Social, y luego participó en el diario Concordancia, órgano del bloque de diputados del socialismo independiente creado a partir de 1930. En 1933, como diputado nacional, presentó el proyecto y promovió la sanción de la Ley de Propiedad Intelectual o Ley Noble. En 1936 se convirtió en Ministro de Gobierno de la Provincia de Buenos Aires durante el mandato del conservador Manuel Fresco y, finalmente en 1939 abandonó la actividad política.
} 
En su primer editorial el diario se autodenominó como un medio "informativo e independiente sin vinculaciones con las agrupaciones políticas tradicionales" (Ulanovsky, 2005, 109) ${ }^{18}$.

Entre 1945 y 1950 ventas, acciones e influencia del diario subieron. Entre los motivos de ese éxito se puede destacar que el diario llegaba a los puntos de venta de la Capital Federal, antes que los otros (Ulanovsky, 2005). Sin embargo, más allá de la escasez de recursos del diario y la ayuda estatal de la que se valió para seguir publicándose, Sivak (2013) remarca la astucia de Noble para comprender el mundo de la prensa y visualizar oportunidades comerciales. Así, por ejemplo, a posteriori de la expropiación del periódico La Prensa en 1951, líder en ventas y publicidad, Noble supo quedarse con el negocio de los avisos clasificados (García, 1997; Sivak, 2013).

En lo que atañe a las relaciones de Clarín con el primer peronismo, Sivak (2013) asegura que buscó hallar acuerdos con Juan Domingo Perón. Encontró en Raúl Apold, jefe del aparato de comunicación y propaganda de Perón, un aliado: obtuvo grandes beneficios en la provisión de papel, créditos bancarios y publicidad. Sin embargo, Ulanovsky (2005) indica que durante el primer gobierno de Perón sumó fama de "independiente", ya que en 1948 lo clausuraron por vulnerar reglamentos laborales y "tuvo que pelear contra con las cuotas de papel que [...] impuso el gobierno peronista” (p. 112).

Borrelli (2016), por su parte, indica que entre fines de la década del 50 y comienzo de los años 80, Clarín adoptó el ideario político del desarrollismo nacional. El primer desarrollista en trabajar formalmente para el diario fue Oscar Camilión, quien se desempeñó como secretario de redacción y editorialista entre 1965 y 1972.

Hacia 1975, Clarín explicitó cierta ambivalencia en su posición editorial sobre el rumbo que había tomado el gobierno de Isabel Martínez de Perón, en tanto que, si bien por un lado sostenía que la crisis debía resolverse dentro del marco institucional, por el otro apoyó la intervención de las Fuerzas Armadas en la represión de la guerrilla en todo el país, y descalificó las propuestas de los actores políticos que consideraba "negativos" como, por ejemplo, "sindicatos peronistas, partidos políticos, el gobierno, el parlamento" (Borrelli, 2016, p. 86).

Durante la dictadura, el diario defendió al régimen militar a la vez que criticó la política económica de José Alfredo Martínez de Hoz (Borrelli, 2016). Y, debido a su capacidad para "adaptarse" a la época, obtuvo junto a La Nación y La Razón acciones en

\footnotetext{
${ }_{18}$ En lo que respecta a las fuentes de financiamiento iniciales, si bien Noble contaba que había vendido una estancia y que con ese dinero había invertido en bobinas de papel, en su investigación sobre el matutino, Sivak (2013) pone en cuestión la versión del fundador a partir de dos datos que le permiten desmentirlo: la transacción fue cerrada después del lanzamiento de Clarín, Noble obtuvo dinero de un grupo de empresarios y gran parte del papel le fue provista por el periódico nacionalista Cabildo (Sivak, 2013).
} 
Papel Prensa S.A. ${ }^{19}$. Hacia 1976, Clarín respondía a los intereses del Ejército (Borrelli, 2011) y durante los años 70 fue uno de los periódicos fundadores de Fapel, una sociedad que integraba con La Nación y cuyo objetivo era dedicarse a la producción de papel para periódicos. Luego del accidente aéreo del empresario David Graiver ${ }^{20}$, ocurrido en agosto de 1976, el gobierno militar encabezó una cruzada para confiscar las propiedades que habían pertenecido al banquero, y ofreció las acciones de Papel Prensa a los cuatro diarios de mayor circulación del país (Clarín, La Nación, La Razón y La Prensa, que rechazó el ofrecimiento). Finalmente, el 2 de noviembre de 1976 el gobierno militar obligó a la viuda de Graiver, Lidia Papaleo, a firmar el preboleto de venta de las acciones de la empresa a Fapel S.A. ${ }^{21}$ Esto explica la tendencia hacia una actitud condescendiente de estos medios hacia el régimen.

A partir de 1976 la sección Internacionales, que era la primera sección del diario, fue reemplazada por la de Política y como parte de la renovación que impulsó el secretario general, Marcos Cytrynblum, Clarín otorgó mayor parte de su superficie redaccional a los deportes, los policiales y los espectáculos, con abundancia de fotografías. Según De Rússovich y Lacroix (1986), con estos cambios se buscó construir un producto periodístico que llegara a amplios sectores de la sociedad, con el fin de consolidarse como un periódico de circulación masiva.

Finalmente, según documenta la investigación de Sivak (2015), a principios de 1982 la viuda de Noble, Ernestina Herrera, ya devenida directora del diario desde 1969 hasta 2017, momento de su fallecimiento, se desprendió de Frigerio y con ello del desarrollismo. Héctor Magnetto, ${ }^{22}$ que había ingresado en la década anterior, se convirtió en el nuevo número uno y actuó como el brazo operativo que profesionalizó la empresa, para contar con mayor libertad de acción en el mundo de la política y los negocios.

\section{Crónica (1963)}

El 29 de julio de 1963 apareció el vespertino Crónica, que ocupó el lugar que había dejado vacante Crítica como diario amarillo local un año antes. Desde su aparición se orientó a un lectorado de corte popular susceptible a las notas de alto impacto como los crímenes, las catástrofes, etc.

\footnotetext{
${ }^{19}$ Sobre este tema se recomiendan las lecturas de Sivak (2013) y Borrelli (2011).

${ }^{20}$ David Graiver fue un empresario argentino. Encabezaba un grupo financiero conformado por bancos, medios de comunicación, y acciones en Papel Prensa, las cuales había adquirido hacia 1973, con la ayuda del ministro de Economía de Isabel Martínez de Perón, José Ber Gelbard. Graiver, vinculado a la organización Montoneros por administrar su dinero (Gasparini, 2007), murió en un accidente aéreo en agosto de 1976. Sobre su muerte se elucubraron varias versiones: algunos decían que no había muerto, sino que habría fraguado su final para quedarse con dinero de Montoneros, otros sostenían que los propios Montoneros lo habrían matado, y una tercera versión afirmaba que los militares habían sido los responsables de su deceso.

${ }^{21}$ Fapel S.A. se había creado para construir una planta ante la eventualidad de quedar fuera del demorado proyecto de Papel Prensa; hacia 1976 solo tenía una existencia formal (véase Borelli, 2011).

22 Actualmente Magnetto es CEO del grupo Clarín.
} 
Según relata Ulanovsky (2005), el fundador y director, Héctor Ricardo García ${ }^{23}$, fotógrafo y periodista, sostenía que el diario se vendía primero por su sección Deportes, luego por la información de espectáculos seguida por las de turf, las policiales, los juegos de azar y finalmente por los temas políticos.

La tirada de Crónica creció a lo largo de los años y llegó a desplazar en algunos momentos a La Razón. Ulanovsky (2005) sostiene que el crecimiento de ventas de Crónica se vinculó antes que con el periodismo con la picardía de su fundador. Cuando la multinacional Pepsi, para instalarse en el mercado de las líneas colas, sacó un concurso de preguntas y respuestas con premios fabulosos, el lanzamiento abarcó a todos los medios menos a Crónica. Por este motivo, García, sin decir de qué concurso se trataba en cada edición del diario, adelantaba una respuesta y "se calcula que con este ardid vendió 10000 ejemplares más por jornada” (Ulanovsky, 2005, 221-222).

De hecho, la competencia que significaba Crónica obligó a La Razón a ubicar por primera vez una noticia policial en primera plana. Según cuenta García (1997) "el crecimiento de Crónica asustó a los directivos de La Razón, especialmente a su conductor, Félix Laiño, quien reaccionó comenzando a darle gran espacio al 'Caso Penjerek ${ }^{24}$, que llevó a la primera página, cosa inusual en un diario destinado, supuestamente, al público mal calificado como 'serio"' (p. 52).

García (1997) relata que Crónica fue clausurado en reiteradas oportunidades por distintos gobiernos, democráticos y dictatoriales. Hacia septiembre de 1976, el diario declaraba en la parte superior de la tapa que su circulación era de 530.500 ejemplares, aproximadamente.

Durante su carrera, García sufrió varias veces actos de censura. Crónica fue varias veces clausurado por violar prohibiciones de los gobiernos de turno: en 1970, durante el de Juan Carlos Onganía, por publicar información sobre el Cordobazo; en 1974, por

\footnotetext{
${ }^{23}$ García inició su trabajo en los medios de comunicación en 1950 con la revista Sucedió, de muy corta duración. En 1954 editó Así es Boca; un año más tarde creó la revista Así, que llegó a tener tres ediciones semanales. En abril de 1963 lanzó el diario Crónica. En 1965 fundó la Editorial Sarmiento S.A., y más tarde los semanarios Ahora y Flash y el diario Democracia. En 1965 adquirió Radio Colonia, ubicada en la ciudad homónima de Uruguay pero con importante llegada a la Argentina, y en 1970 hizo lo mismo con Teleonce, al que logró llevar al primer puesto de audiencia; de esta manera se convirtió en el dueño del mayor multimedios del país en su momento. En 1973 las televisoras privadas fueron intervenidas por el Estado Nacional, lo que fue ratificado al año siguiente por decreto del gobierno de María Estela Martínez de Perón, con lo cual García perdió el mando de Teleonce, aunque continuó manejando sus otros medios, a los que sumó en 1979 el diario El Atlántico de Mar del Plata. Como empresario teatral, en 1972 adquirió el Cine Ástor sobre la avenida Corrientes en Buenos Aires, y lo transformó en el Teatro Astros; en 1975 creó el Complejo Estrellas, y más tarde se hizo cargo del Teatro Tronador de Mar del Plata. Véase García (1997).

${ }^{24}$ El caso se refiere al asesinato de Norma Mirta Penjerek, ocurrido un mes después de la aparición de Crónica. García recuerda que fue un caso que explotaron "al máximo" y que provocó un crecimiento de la circulación a más de 50.000 ejemplares (García, p. 51).
} 
orden de José López Rega ${ }^{25}$, y durante un año, por invocar una campaña a favor de las Islas Malvinas; ya con Jorge Videla en el poder, en 1976 por publicar la noticia de la muerte de Mario Santucho, líder del Ejército Revolucionario del Pueblo (ERP), y luego en 1978, por anunciar una supuesta apertura política del gobierno. A esto se suman atentados, como el de fines de 1975 contra su complejo teatral para impedir el estreno de una obra de Nacha Guevara (García, 1997; Ulanovsky, 2005).

Respecto de la clausura de diciembre de 1974, García (1997) recuerda que luego de financiar durante dos meses, con dinero propio, el sueldo de casi 1000 empleados que tenía Crónica, Graiver, detrás de quien estaba el ya mencionado ministro José Ber Gelbard, se acercó para proponerle realizar un diario que él editaría, bajo la dirección de Délfor Otero. Hacia febrero de 1975 el diario Última Hora se imprimía en Crónica y empleaba a todo su personal. Vale destacar que durante el período de la dictadura se ordenó investigar las conexiones económicas de García con el grupo Graiver (García, 1997).

El 17 de diciembre de 1975, la Corte Suprema de Justicia ordenó levantar la clausura de Crónica: "y a los dos días, el viernes 19, desaparecía Última Hora, se anulaban todos los contratos entre Graiver y 'Editorial Sarmiento S.A., y todo volvía a la normalidad" (García, 1997, p. 97).

En el marco de una farragosa relación con las autoridades del "Proceso", Crónica apoyó la "lucha antisubversiva"; sin embargo, le dedicó una extensa cobertura a la visita que realizó en 1979 la Comisión Interamericana de Derechos Humanos a la Argentina. Durante la contienda de la guerra de Malvinas, Crónica acompañó el tono triunfalista que caracterizó a gran parte de la prensa ${ }^{26}$.

\footnotetext{
${ }^{25}$ José López Rega fue un político y policía argentino. Apodado el “Brujo", por su inclinación hacia prácticas esotéricas, se desempeñó como ministro de Bienestar Social en los gobiernos de Héctor Cámpora, Raúl Alberto Lastiri, Juan Domingo Perón y, a posteriori de su muerte, en el de Isabel Martínez de Perón. Durante este último gobierno creó un grupo parapolicial denominado Alianza Anticomunista Argentina (Triple A). Esta banda de derecha que, desde noviembre de 1973, era conducida por López Rega, se caracterizó por asesinar a militantes políticos y sociales de izquierda y por amenazar a intelectuales, políticos y personalidades de la cultura, que se oponían a la derechización del gobierno (Vezzetti, 2002). El giro conservador de Isabel Perón en materia política tuvo su correlato en materia económica: el intento de ajuste liberal estructural, que en junio de 1975 anunció el ministro de Economía Celestino Rodrigo, promovido por López Rega. El "Rodrigazo", nominalización hiperbólica que se utiliza para referirse a los resultados nefastos de aquel plan económico, generó la oposición del sindicalismo peronista, que objetaría el intento de ajuste, y que implicó el final de la experiencia de López Rega en el poder y el inicio del fin del gobierno peronista (De Riz, 1986).

${ }^{26}$ De todos modos, es pertinente destacar que la cobertura que realizó Crónica sobre el conflicto bélico se explica por el interés de García sobre las Malvinas. El 28 de septiembre de 1966, un comando armado de 18 estudiantes, obreros, sindicalistas y periodistas, en su mayoría militantes peronistas y nacionalistas, secuestró un avión Douglas de Aerolíneas Argentinas, que había partido desde Buenos Aires y tenía por destino a Río Gallegos, lo desvió, y lo hizo aterrizar en las Islas Malvinas unas horas más tarde. Los jóvenes se llamaban a sí mismos "cóndores". El Operativo Cóndor, como fue bautizada la acción armada, fue comandado por Dardo Cabo, de 25 años de edad, periodista, metalúrgico y activo militante peronista nacionalista, hijo del sindicalista Armando Cabo. García se encontraba entre los miembros del Operativo Cóndor.
} 


\section{Resultados}

En el presente apartado tomaremos los siguientes casos de análisis: por un lado, el atentado contra el primer jefe de la Policía Federal de la dictadura, ocurrido en junio de 1976 e inscripto en la agenda de lo que denominamos "delito subversivo". En segundo lugar, nos referiremos al caso Murano, inscripto en la serie informativa de crímenes espectaculares. Finalmente, nos detendremos en el caso del ladrón de cables de electricidad y del ladrón de sábanas blancas y órganos electrónicos, de la agenda del delito común.

\section{La delincuencia subversiva}

En el caso particular de los crímenes "cometidos por la subversión" que forman los sumarios de los periódicos que estudiamos, podemos afirmar que son similares en su clasificación, aunque emplean modos de cobertura propios, dependientes del contrato de lectura ${ }^{27}$ y, en menor medida, de la agenda atributiva. Sostenemos esta apreciación porque durante los primeros años de la dictadura se advierte no solo uniformidad en los criterios utilizados por los medios para definir qué cuestiones eran noticiables sino también coincidencia en cómo se debían pensar esas cuestiones. Desde luego, esto se explica por la censura y la persecución que caracterizó al período y por la "imposición" desde las esferas castrenses de lo "decible y escribible" (Angenot, 2010, p. 29) en las agendas periodísticas.

Así durante el período 1976-1978 la "subversión política” y su “aniquilamiento", que la prensa traducía como "enfrentamientos con las fuerzas de seguridad" ocupaban la centralidad de la agenda periodística ${ }^{28}$, inclusive en medios como Crónica, cuya oferta informativa se caracterizaba (y se caracteriza) por privilegiar las noticias sobre deportes, policiales y espectáculos. En lo que sigue a continuación nos detendremos en el análisis de la cobertura noticiosa del caso Cardozo. Lo consideramos sumamente ilustrativo para los fines de este trabajo puesto que involucra al general Cesáreo Cardozo ${ }^{29}$,

\footnotetext{
${ }^{27}$ Este aspecto se advierte en rasgos estilísticos utilizados por cada diario. Por ejemplo: mientras Clarín presentaba las noticias vinculadas a "la lucha contra la subversión" bajo títulos como "Abatieron" o "Murieron sediciosos en un enfrentamiento con las fuerzas de seguridad", medios como Crónica, que reproducía textualmente en el cuerpo de la nota el mismo comunicado oficial que sus competidores, titulaba utilizando la hipérbole narrativa, recurso de exageración propio del policial pero también del estilo sensacionalista que caracteriza a la prensa amarilla. Por ejemplo, "Ocho muertos en un encarnizado tiroteo" (Crónica, 1/6/1976, Tapa).

${ }^{28}$ De acuerdo con los planteos de Van Dijk (1997) la presentación de las noticias (ubicación en tapa, utilización de fuentes) como la permanencia temporal de estas en la agenda informativa de McCombs y Shaw (citados en Martini y Gobbi, 1998) denotan relevancia e importancia de los temas, los actores y los sucesos. Teniendo en cuenta lo anterior, advertimos la centralidad del "delito subversivo" en la agenda informativa, puesto que durante el período 1976-1977 entre el 30\% y el 50\% de las unidades noticiosas en tapa ( 2 a 3 noticias sobre un total de 6) se referían o bien a las "víctimas de la subversión" (por ejemplo, el caso del General Cardozo), o bien a las series inscriptas en lo que llamamos la agenda del "delito subversivo".

${ }^{29}$ Cardozo era jefe de la policía desde el 31 de marzo de 1976. Había egresado del Colegio Militar como subteniente de infantería en 1947.
} 
primer jefe de la Policía Federal Argentina de la dictadura, considerado el tercer hombre de importancia en la lucha contra la guerrilla, quien murió por la explosión de una bomba colocada por Ana María González, militante de la organización Montoneros, debajo del colchón de su cama.

\section{El caso Cardozo (1976)}

Los actores de las noticias. Hay coincidencia en los estudios de la noticia policial al afirmar que la alusión a víctimas y victimarios permite la identificación del público con uno de los "bandos". Ahora bien, ¿cuáles fueron los actores involucrados en los hechos criminales que se tematizaban en la agenda del "delito subversivo"?, ¿qué imágenes se construyeron acerca de estos?, ¿qué acciones se describían y cuáles se omitían?

El caso Cardozo se inscribe en la serie informativa que denominaremos atentados contra las fuerzas policiales y de seguridad. En estas noticias se identifican dos actores principales: las fuerzas de seguridad identificadas como "los agentes del bien" y la subversión en tanto "el enemigo interno". Se trata de dos actores activos y antagónicos: los primeros embarcados en la "lucha antisubversiva" y los segundos, en tanto "agentes apátridas marxistas", desestabilizadores del orden social. En el caso analizado, los actores principales son el "héroe-víctima del delito subversivo" -general Cesáreo Cardozo- y la "asesina subversiva”, Ana María González $z^{30}$. Como actor-víctima secundaria aparece la "Nación", que opera discursivamente como la gran "víctima colectiva", que pide por el aniquilamiento de la "subversión".

En relación con las fuerzas de seguridad y sus miembros en particular, las noticias las presentaban en un doble rol: héroes y víctimas de la subversión.

Van Dijk (1997) afirma que los asuntos más importantes de la estructura temática de un discurso aparecen en sus titulares puesto que "expresan la macroestructura semántica preferencial, programan el proceso de interpretación y aportan una definición (subjetiva) de la situación". Y a partir de estas macroproposiciones podemos observar, entre otras cuestiones, qué temas y actores tienden a aparecer en los títulos, así como las implicaciones ideológicas.

De este modo en las coberturas sobre la muerte de Cardozo, se aprecian titulares y bajadas o resúmenes como las que se detallan a continuación:

"Estupor ante el bárbaro atentado" (Clarín, 20/6/1976, p. 4).

\footnotetext{
30 Ana María González era una joven militante de Montoneros, estudiante del profesorado de nivel inicial y compañera y amiga de Chela, la hija de Cardozo. Luego de colocar la bomba que terminó con la vida del militar, pasó a la clandestinidad. Sobre la figura de Ana María González se recomienda la lectura del libro del historiador Federico Lorenz (2017), de reciente aparición.
} 
"Asesinan al Jefe de la Policía Federal". Indignación familiar: la delincuencia subversiva traicionó la amistad; una joven amiga de la hija del General Cardozo le puso una bomba en la cama (Crónica, 18/6/1976, Tapa).

Como puede advertirse, la valoración de lo acontecido giraba en torno a la idea de "asesinato" y "atentado". Las formas impersonales aluden al "responsable", la subversión. Si tenemos en cuenta que, tal como sostiene Van Dijk (1997), "los datos del discurso no deben ser descriptos aisladamente sino en relación con el texto (co-texto) en conjunto y con respecto al contexto: quién está hablando con quién, cuándo y con qué intención" (p. 108) podemos decir que la ausencia de nominalización explícita del sujeto de la acción criminal logra enfocar la atención en las víctimas de la acción violenta, en este caso el general Cardozo. Como muestran los títulos, la alusión a la figura del jefe de la policía es explícita e identificable del lado de las "fuerzas de seguridad", actor clave de "lucha contra la subversión", y en el rol de la víctima del accionar de la "delincuencia subversiva”.

Es interesante notar que si bien se aprecia uniformidad informativa en las agendas periodísticas temáticas (el qué) y atributivas (el cómo), los diarios amarillos se diferencian del resto de sus competidores a partir de los rasgos estilísticos asociados con su contrato de lectura. Así Crónica, cuando asevera que la "subversión es capaz de traicionar la amistad", apela a una modalidad del decir en clave melodramática. Este mecanismo es efectivo a los fines de un discurso punitivo y moralizante propio de la prensa popular: en virtud de la defensa del valor sagrado de la amistad, exacerba el comportamiento inmoral del "delincuente subversivo".

En lo que respecta a la representación mediática de la victimaria, esta es estereotipada a partir de la caracterización militar de la "subversión" como "enemigo interno" de corte marxista con alto poder de camuflaje e infiltración. De aquí que la identificación de Ana María González resultase altamente redituable para poner rostro a la subversión a la vez que aleccionador sobre el rol y la responsabilidad de la familia en la preservación del hogar "de las ideas nefastas de la izquierda marxista". La "responsabilidad de los padres" era un tópico recurrente en el discurso militar, que los medios no tardaron en replicar funcionando, en algunos casos, como meros soportes de la difusión de la cadena nacional del "disciplinamiento y el orden".

Por su parte, Clarín, con el objetivo de dar cuenta de las motivaciones sobre las cuales se sustentaba el accionar subversivo, articulaba en sus crónicas características psicológicas y detalles de la historia familiar.

Las fuerzas de seguridad. Fuentes de información y garantes del orden social. La cercanía que manifestaban todos los diarios estudiados al utilizar constantemente como fuente de información a los comunicados emitidos desde las esferas castrenses se vincula con el contexto particular en el que se encontraba el país. Es importante señalar que los 
comunicados de las Fuerzas Armadas alimentaban las series, inscriptas en la agenda del "delito subversivo", que informaban "sobre el enfrentamiento/choque entre fuerzas de seguridad y elementos sediciosos". Pero también se nutría de la fuente policial, no solo en casos como el de Cardozo sino también en aquellas noticias que informaban sobre las víctimas -concretas e identificables- "asesinadas" por "la subversión" como, por ejemplo, ocurrió en los casos de la muerte de Paula Lambruschini ${ }^{31} \mathrm{y}$ del asesinato de los curas palotinos ${ }^{32}$, en los que, al darse aviso a las comisarías más cercanas, la policía se convertía en la primera fuente autorizada de información.

Como era característico de la época, frente a cada crimen cometido por la subversión los medios reproducían distintos comunicados oficiales con un alto nivel de detalle, que evidenciaban los éxitos del accionar militar sobre la guerrilla.

Las fuentes de información que se utilizaron en las noticias sobre la "lucha antisubversiva" durante el período eran predominantemente las oficiales y eventualmente testimonios de vecinos que permitieran aportar datos clave sobre el entorno del subversivo. Así se observa en el caso del atentado contra Cardozo:

[...] hay un vecino que es el único que habla de "las ideas de izquierda" que atribuye al médico González [en relación con el padre de Ana María, autora del atentado]. Asegura que hace un tiempo tuvo un problema en el Hospital de San Fernando precisamente por esa causa y debió retirarse del establecimiento. Y agrega: "es extraño. Tenía fama de ser un gran médico. Tengo entendido que participó en congresos científicos en el exterior, pero no tenía chapa en la puerta (Clarín, 20/6/1976, p. 4).

Es importante notar, en este ejemplo, la inclusión de la voz de un vecino, "el único que se animaba a hablar" pero que, sin embargo, a la manera de "vigilante de la cuadra", se atrevía a instalar sospechas sobre una familia de "apariencia normal" a partir de señalar la ausencia de la chapa médica identificatoria del padre de la "delincuente". Las inclusiones de este tipo de testimonios ponen de manifiesto la ubicuidad, la labilidad y la presencia en cada intersticio del entramado social (Foucault, 1985) de los mecanismos de sospecha, alarma y vigilancia y el modo en que se ejerce de manera capilar en vínculos familiares o lazos íntimos.

\footnotetext{
31 Paula era hija del almirante Armando Lambruschini (en ese momento era el Jefe Naval sucesor de Emilio Eduardo Massera). Falleció en agosto de 1978, como consecuencia de la detonación de un artefacto explosivo colocado en un departamento lindante al suyo.

32 Aunque los comunicados oficiales los señalaban como los responsables, Montoneros no asesinó a los religiosos (tres curas palotinos y dos seminaristas), sino que fueron los propios militares. Cabe destacar que estos religiosos estaban vinculados al Movimiento de Sacerdotes del Tercer Mundo. Las declaraciones favorables al cambio social y político expresadas por el movimiento se remitían a la autoridad de los documentos Vaticano II (1962-1965), Populorum Progressio (1967), Medellín (1968), San Miguel (1969) (Paz, 2003). En vistas de un orden social y económico injusto para el conjunto de la humanidad, este movimiento reorientó su trabajo pastoral hacia los sectores más humildes. Esa "renovación" generó intensos debates dentro de las iglesias latinoamericanas entre sectores renovadores, que se adhirieron a estos cambios, y los más conservadores. La persecución hacia los sacerdotes alineados con este movimiento ya era visible antes de la dictadura; un ejemplo de ello es el asesinato de Carlos Mugica en 1974, en manos de la Triple A.
} 
La legitimación de las fuentes de información en el discurso periodístico provenía de su identificación, personificación y pertinencia (Van Dijk, 1997). De este modo encontramos ejemplos, citados predominantemente en estilo directo, con un grado preciso de identificación de la fuente "Comando del I Cuerpo de Ejército" (Clarín, 20/6/1976, p. 4), lo que expresa de ese modo respeto y veracidad por la fuente. En otros casos el nivel de personalización es mayor: "el director del Colegio Militar de la Nación, general Reynaldo Antonio Bignone” (Clarín, 20/6/1976, p. 3).

La pertinencia se hallaba en que la información emanaba de los responsables directos de instituciones públicas, hubieran o no participado de los hechos.

La ponderación que se realiza desde el discurso de la prensa es positiva tanto para con las fuerzas policiales como las militares, a las que se presenta también como un sector homogéneo ${ }^{33}$ ("fuerzas de seguridad"), aunque les asignaban distintos ámbitos de actuación: los sectores castrenses aparecen interpelados en el rol de "agentes" al servicio de la "restauración del orden social interno" en la "lucha contra la subversión"; las fuerzas policiales, por su parte, debían complementar a las primeras y además actuar enérgicamente en la prevención y combate del "delito común".

Así, respecto de las Fuerzas Armadas, Clarín pregonaba que la guerra contra la "subversión" se debía extender a todos los órdenes, puesto que funcionaba con "activistas infiltrados" en ámbitos como el universitario, el político o el gremial ${ }^{34}$. En consecuencia, para que el gobierno "pudiera concentrarse en los problemas fundamentales"35 el aniquilamiento de los "elementos rebeldes" volvía necesaria una alianza pueblo-Fuerzas Armadas, porque habiendo tomado la comunidad conciencia de las causas que "habían motivado"36 el proceso iniciado el 24 de marzo de 1976 y por ende de la verdadera dimensión de la acción "subversiva", las Fuerzas Armadas debían construir el monopolio de la fuerza asociando a los distintos sectores en la lucha permanente contra la "subversión". Cabe destacar que los diarios retoman la figura del "subversivo" o "extremista", como enemigo interno a "eliminar", de los diarios del discurso militar, en los años 60 (Casabona, 2013). Por lo tanto, no constituye una novedad propia del período, aunque la subversión sí adquiere centralidad en la agenda periodística como figura delictiva predominante, sobre todo en el período 1976-1978.

\footnotetext{
${ }^{33}$ Las “disputas y/o enfrentamientos" entre las Fuerzas Armadas y la policía, que exceden por completo el objeto de esta investigación, son omitidas en los diarios. Respecto de esta temática, entre otros, véase Oliveira y Tiscornia (1997).

${ }^{34}$ Así, por ejemplo, el diario sostenía: "Fue desbaratada una vasta red subversiva que tenía como centro operativo a la Universidad Nacional del Sur, en Bahía Blanca (...) donde los extremistas -en su inmensa mayoría docentes universitarios- ejercían una penetración ideológica" (Clarín, 5/8/1976, p. 10).

35 Entiéndase: problemas de índole económica (Clarín, 1/8/1976, p. 20).

${ }^{36}$ Las causas que, según el diario, motivaron el golpe de Estado, remitían a los tiempos en los que no había forma de dominar la guerrilla: "cuando se operaba en el país un vacío de poder, acompañado por la desorganización del Estado y el entronizamiento de cúpulas irrepresentativas y corruptas no solo en las esferas de su conducción sino también en las organizaciones gremiales, de trabajadores y empresarios institucionalizadas por la legislación" (Clarín, 1/8/1976, p. 20).
} 
De esta manera, y ante acontecimientos como el de Cardozo, se exponían una y otra vez una legitimación de los usos y de los métodos represivos sobre quienes era legítimo ejercer el control y la disciplina, y la diferencia entre quienes estaban del lado de la ley y quienes no.

Tal como sostiene Voloshinov (1976) el signo es el espacio en el que se expresan las bases materiales de una ideología y donde tiene lugar la lucha ideológica, es decir, donde cada grupo o sector querrá imponer su sentido, su visión del mundo. Esto se aprecia concretamente en la monoacentuación del sentido heroico del accionar de la policía y de las fuerzas de seguridad y, en contrapartida, en los señalamientos despectivos dirigidos a deslegitimar la práctica de los integrantes de las organizaciones político-armadas Matías, mantener junta la expresión con guiones, además de obviar las razones políticas que explicaban sus orígenes y trayectoria.

La "lucha antisubversiva" y el contrato de lectura. Tal como señalan Ford, Martini y Mazziotti (1996), hay dos áreas en los diarios: las zonas duras (política nacional, política internacional y economía) y las zonas blandas (espectáculos, policiales e información en general). Mientras que las primeras se apoyarían en un tipo de discurso informativo y argumentativo más abstracto y estructural; las segundas lo harían en un discurso más narrativo, casuístico, concreto y personalizado, que sin embargo tiene una fuerte conexión con el discurso didáctico o moralizante, o con el ideológico y pone en juego diversos sistemas de generalización, aun sin tener la estructura interna de la argumentación.

En relación con este punto nuestro análisis sostiene que si bien cada medio proponía un contrato de lectura específico a sus lectores, en virtud del cual construían sus agendas, como así también la selección y jerarquización de la información, las noticias sobre la subversión se narraron en clave informativa -en un discurso en el que ni el enunciador ni el destinatario estaban explícitamente marcados- pero apelando a una retórica de tipo delictivo.

Aquí se configura una imagen del "subversivo" en términos delincuenciales a partir de la utilización de expresiones como "asesina", "autora", "estuvo detenida", "colocó la bomba" -retórica propia del género policial-. Es desde este tipo de operaciones discursivas como se consolida un esquema interpretativo que da lugar a la configuración de una narrativa autoritaria y represiva que demandaba específicamente mayor control social y el restablecimiento de un orden perdido.

De todos modos, es conveniente señalar que Clarín se caracterizó por presentar una diagramación prolija -a diferencia de Crónica, que ubicaba en una misma página los avisos fúnebres, el resultado del turf y los relatos sobre la muerte de Cardozocontaba con secciones variadas que permitían una ordenada presentación de las noti- 
cias. Por lo tanto, la jerarquización de la delincuencia subversiva como una noticia de Política (Clarín) era fácilmente identificable por el lector.

\section{La agenda policial: asesinatos y "delitos comunes"}

La crónica, género periodístico mayoritariamente utilizado para narrar las noticias sobre el delito común, ofrece a los periodistas la posibilidad de utilizar recursos literarios en un género de no ficción. No solo se informa sobre un hecho en particular, sino que la importancia fundamental de este género reside en cómo se narra esa historia. El periodista es detective y cronista al mismo tiempo ${ }^{37}$.

Ahora bien, en el período que nos importa la narración del "delito común" despliega núcleos argumentativos específicos según se trate historias de asesinos de "alta peligrosidad" o "ladrones de gallinas". De este modo, advertimos que en las series informativas, por ejemplo, de infanticidio, envenenamiento y parricidio la narración de sucesos criminales muestra un rasgo estilístico fundamental del género: lo sensacionalista y el espectáculo sangriento y macabro. Pero también notamos la utilización de la retórica de corte autoritario/represivo que se había desplegado en las series informativas inscriptas en la agenda del delito subversivo. Esto se aprecia, por ejemplo, en las coberturas sobre "Yiya" Murano, la "envenenadora de Monserrat", a cuyas víctimas asesinaba por envenenamiento con cianuro.

La narración de crímenes espectaculares y los actores de la noticia: la "envenenadora de Monserrat" (1979)

El 23 de mayo de 1979, Clarín informaba en su sección policial que dos crímenes se habían confirmado y otros dos quedaban pendientes de confirmación: por lo menos tres mujeres habían muerto por envenenamiento a manos de otra, y además dos cadáveres -también de mujeres- esperaban ser exhumados del cementerio de la Chacarita (Clarín, 23/5/1979, pp. 36-37).

Si tenemos en cuenta que los criterios de noticiabilidad se basan en la "novedad", en la ruptura que produce en la cotidianeidad o lo esperado y la gravedad, el acontecimiento (sucesivas muertes por envenenamiento) y los personajes involucrados resultaban altamente noticiables y provechosos si se buscaba mantener cautiva la atención de los lectores, sobre todo para el decano del policial como Crónica. El énfasis dado a este acontecimiento lo advertimos teniendo en cuenta el modo de presentación de la

\footnotetext{
${ }^{37}$ La crónica periodística es un relato cronológico de hechos, acontecimientos e historias, considerado como un género híbrido, interpretativo (Díaz Noci, 1995) puesto que si bien incorpora ciertos elementos de valoración e interpretativos (característicos de los géneros de opinión) estos siempre tienen un carácter secundario frente a los elementos estrictamente informativos (propios de los géneros informativos como la noticia). Por su parte, Brunetti (2011) agrega que la crónica periodística ha sido incluida siempre en los estudios sobre las llamadas "literaturas populares", desde cuya discursividad se infiere un lector popular. Sin embargo, esto no significa que otros lectores se hayan sentido atraídos por esta narratividad y fueran asiduos compradores de novelas populares o consumidores de crónicas policiales.
} 
noticia: el caso ocupó en el transcurso de dos meses (mayo y junio de 1979) las primeras planas de los diarios aquí analizados. El mayor o menor centimetraje otorgado a las unidades informativas sobre los envenenamientos variaba de modo proporcionalmente directo a la "evolución" de la investigación.

Clarín moldeó la figura de Yiya Murano, la asesina, sobre la base de la de Lucrecia Borgia (Clarín, 24 de mayo de 1979, pp. 38-39); "depravadas y promiscuas", incestuosa esta última, estafadora la otra, pero fundamentalmente expertas en servir pócimas envenenadas a los invitados con elegante ademán y también sonrisa obsequiosa. Su personalidad desconcertaba, rompía con el estereotipo de mujer "de clase media acomodada": "era jovial y muy comunicativa. Tenía amistad con dos hombres. Su arresto se produjo al término de un 'capolavoro' cumplido en el gabinete de Toxicología de Medicina Legal de la División Homicidios" (Clarín, 24/5/1979, pp. 38-39). Su figura mafiosa se veía potenciada por la compleja trama de corrupción en que se sostenía: médicos y veterinarios - actores secundarios, incluidos en la serie como agentes activos- que habían falsificado certificados de defunción y le habían conseguido el veneno.

La inclusión de formas coloquiales de expresión -como "la Murano"- funcionaban como mecanismo textual que reemplazaba el título de "señora” y la convertían en una "cualquiera", una más.

En los casos de asesinato las narrativas mediáticas evidenciaban uniformidad en el encuadre interpretativo: el grado de cercanía entre el homicida y la víctima, el tipo de víctima (infante, familiar, amigo) y el método empleado eran las variables en función de la cual los medios desplegaban núcleos argumentativos en torno el grado de severidad de la pena. También lo era la cantidad de víctimas, y así lo enfatizaban los titulares de los medios estudiados. Algunos ejemplos:

“¿Ocho víctimas de la bienuda asesina?” (Crónica, 26/5/1979, pp. 5-6).

"Ascienden a siete las víctimas de la envenenadora" (Clarín, 24/5/1979, pp. 38-39).

En lo que atañe a las víctimas - una prima y dos amigas de la asesina, a quienes se les asigna el rol de agentes pasivas en tanto engañadas- eran delineadas como personajes non sanctos, prestamistas, timberas (Crónica, 26/5/1979, pp. 5-6), pero atrapadas en una historia con un desenlace escalofriante y "sin precedentes, con un final inmerecido". Los diarios aquí analizados utilizaban la estrategia, además, de colocar en el centro de atención la cercanía con las víctimas, en el caso de Clarín de modo especialmente manifiesto en las crónicas que incluían "la voz autorizada" del psiquiatra y del especialista penal (Clarín, 24/5/1979, p. 39).

Una caracterización peculiar recibió el marido de Murano. Actor secundario -por momentos pasivo, por momentos activo- asumiendo, a la vez, el triple rol de "marido 
engañado", "abogado defensor de su mujer" y a la vez "sospechado de complicidad" (Crónica, 24/5/1979, pp. 5-6). Así era retratado por Crónica:

Un hombre hosco, nervioso, con evidentes síntomas de preocupación nos abre la puerta del departamento y se identifica como esposo [...] Se niega a hacer declaraciones. Nos indica un sillón para que nos sentemos. Inmediatamente después nos pide que nos retiremos. Solo musita: 'Se trata de un error. Mi mujer no puede ser una asesina. Ustedes verán que pronto todo se aclarará (Crónica, 23/5/1979, p. 11).

\section{Las fuentes de la información policial}

Los diarios construyen la noticia policial del envenenamiento desde una visión conservadora y positivista de la sociedad, rasgo habitual de la prensa popular que, en el período que nos ocupa, empieza a desplazarse a la prensa llamada seria o blanca. Los medios aquí estudiados -inclusive la prensa blanca como Clarín - toman esos casos y recuperan ciertos rasgos de la "espectacularización" que Saítta (1998) señala para el caso del diario Crítica.

Por una parte, si bien en la construcción de las agendas del delito común las fuentes de información cumplen un rol central, puesto que el periodista no suele ser testigo de los hechos, en el período estudiado, debido a los mecanismos de censura y autocensura y ante la posibilidad de represalias por la publicación de información inexacta o que comprometiera al accionar policial, la fuente o versión oficial era la que necesariamente tenían que tomar los medios. En este sentido, en los periódicos analizados predominan las fuentes oficiales en su denominación generalista - "fuentes judiciales", "fuentes policiales", "los investigadores"- son las que nutren las crónicas sobre el envenenamiento con cianuro.

Por otra parte, si bien la policía es un actor principal y activo en la resolución de los crímenes, como así también una fuente sobrerrepresentada en las noticias sobre "crímenes", en esta serie en particular, el entramado de complicidades entre médicos, casas fúnebres y los "facilitadores del veneno" arrojaron sospechas sobre la posible connivencia de algunos de los miembros de la institución, tal como lo sugieren Crónica y Clarín al advertir un total "hermetismo de las fuentes policiales" sobre el caso. Los diarios explicitan esta sospecha sobre la existencia de una red de complicidad, por ejemplo, en los siguientes titulares:

- "Ante un vallado de silencio" (Clarín, 29/5/1979, p. 32-33).

- "Envenenadora: ¿complicidad de 2 médicos?” (Crónica, 25/5/1979, Tapa).

- "Para meditarlo ¿cómo consiguió el cianuro?” (Crónica, 25/5/1979, p. 8). 
Aun cuando los periodistas prefieren mencionar fuentes fidedignas, como sostiene Van Dijk (1997), en nuestro caso fuentes oficiales, a partir del "vallado de silencio" ${ }^{38} \mathrm{de}$ estas se incluye a la fuente extraoficial encarnada en la voz del vecino:

[...] En esos momentos, el portero del edificio -de nombre Aníbal- algunas ve-

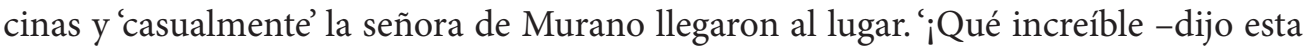
última-. Cada vez que vengo a visitar a mis amigas las encuentro muertas o algo les pasa', dijo a los circunstanciales presentes. En medio de la conmoción lógica, el portero, una vecina del $4^{\circ}$ piso y la Murano penetraron en el departamento de la señora de Venturini. 'En un momento, la Murano tomó un frasco y se lo llevó. Era el que supuestamente contenía restos de cianuro. Esa declaración forma parte de la que hizo al juez el propio portero', dijo otra vecina (Clarín, 29/5/79, pp. 32-33).

Como se advierte en la nota, el grado de identificación de las fuentes variaba de mayor a menor personalización ${ }^{39}$ y la inclusión de las declaraciones de las fuentes respetaba el estilo directo. Con este "mecanismo estilístico" el periodista evitaba "responsabilidad de lo explicitado" puesto que, como sostiene Van Dijk (1997), una cita literal puede expresar deferencia y respeto cuando se trata de una voz autorizada u oficial pero también puede significar distancia y, por ende evitar la responsabilidad de lo explícito, cuando se menciona como fuente a un actor extraoficial.

De todos modos, es significativo indicar que, tal como plantea Marroquín Parducci (2007), los periodistas suelen recurrir a fuentes de segunda mano, no oficiales porque es un recurso que resulta útil cuando la información oficial es escasa y se requiere continuar con las series, tal como puede apreciarse en el ejemplo.

\section{Los "ladrones de gallinas"}

Como mencionamos antes, en la agenda policial convivían asesinos de alta peligrosidad como también delincuentes que hurtaban, robaban o estafaban. Se trataba de "malandras", en algunos casos poco inteligentes, ubicados al margen de la ley, que representaban un menor nivel de "peligrosidad" para la sociedad. Por este motivo, si bien tenían que ser captados por la policía y encarcelados, a diferencia de los delincuentes de alta peligrosidad, cabía la posibilidad de su reeducación en el ámbito penitenciario.

\footnotetext{
38 Clarín aseguraba: "Se tendió un manto de silencio en el intrigante caso de la envenenadora. Nadie sale a explicar por qué lleva treinta y dos días en prisión, ni si las pruebas existentes permiten una irrefutable certeza de su culpabilidad" (...). (“Ante un vallado de silencio", Clarín, 29/5/1979, pp. 32-33).

39 Respecto de los grados de personalización de las fuentes Crónica, por ejemplo, aclaraba: "una vecina, que prefirió no dar a conocer su identidad" (Crónica, 25/5/1979, p. 8).
} 


\section{Los actores de la noticia y la narración de delitos "singulares y absurdos"}

La narrativa de corte correctivo se organiza en torno a ese modelo delincuencial que denominamos el de "ladrones de gallinas". Un ejemplo de este modelo lo constituyen los casos del ladrón que robó un cable de alta tensión, y del ladrón de sábanas blancas y órganos electrónicos. En ambos casos, se trataba de unidades informativas que no recibían cobertura por más de un día. En lo que atañe a las fuentes de información, en las crónicas analizadas se aprecia la referencia a fuentes oficiales en su denominación generalista: "fuentes policiales", la cual nutre tradicionalmente a la crónica policial.

El primer caso se refiere a un joven de 31 años, llamado Gregorio Salinas, quien resultó con quemaduras graves al intentar robar un cable de alta tensión de las instalaciones de Agua y Energía en Villa Constitución.

El segundo hace referencia a Roberto Bunding, quien robaba todo lo que encontraba en su camino para llevarse a su casa: desde órganos electrónicos hasta sábanas blancas.

Todos ocurren en el año 1976, meses después de concretado el golpe de Estado, momento en el que las fuerzas de seguridad estaban abocadas a la "lucha contra la subversión”, lo actual mantenía activados los mecanismos de sospecha, alarma y vigilancia.

Se trata de casos protagonizados por sujetos marginales. En el primer caso, el actor principal -que resulta victimario y víctima- es retratado por los medios como un ladrón ingenuo, despistado y no muy hábil:

Junto al cuerpo del despistado ladrón los policías encontraron cinta aislante y herramientas especiales, lo que pusieron de manifiesto que fue despedido violentamente por la corriente mientras intentaba robar el cable de alta tensión de un transformador, ubicado en las inmediaciones del elevador portuario (Crónica, 6/8/1976, p. 8).

Cuando la policía lo encontró en el suelo y con grandes quemaduras advirtió -por la presencia a su lado de aislantes y herramientas adecuadas- que Salinas había intentado robar un cable de alta tensión de un transformador de Agua y Energía instalado en las cercanías del elevador portuario. No fue muy ducho en tal clase de hecho delictuoso, ya que en un intento sufrió la descarga eléctrica que le produjo quemaduras (pudo haber perdido la vida) (Clarín, 5/8/1976, p. 22).

En el segundo caso, el actor era un cleptómano marginal que había robado aparatos estereofónicos, radios de frecuencia modulada, parlantes, órganos electrónicos, "tres pantalones de corderoy, dos camisetas de frisa siete sábanas blancas y dos toallas" (Clarín, 1/8/1976, p. 10). Según remarcaba Crónica, se trataba de "un ladrón solitario que tenía a mal traer a vecinos y comerciantes del partido de Almirante Brown, desde hacía tiempo" (Crónica, 1/8/1976, p. 6).

El personaje había sido apresado por personal de la policía cuando transitaba por las calles de Burzaco montado en un triciclo de reparto, el cual había sido el fruto de 
su último robo. Aunque trató de explicar a la policía que no era un ladrón sino que simplemente había visto el triciclo y había sentido "ganas de pedalear un rato" (Clarín, $1 / 8 / 1976$, p. 20), en el interior del vehículo la policía halló un equipo completo de música y amplificación, que posteriormente se estableció que Bunding había robado de una confitería bailable de Burzaco. Entre los diversos objetos robados se le hallaron varios órganos (Crónica, 1/8/1976, p. 6). Tras insistir que él no había hurtado los equipos reconoció la autoría de los hechos. Como consecuencia, "una comisión policial se trasladó entonces hasta el domicilio del apresado donde se descubrió una larga serie de elementos producto de las anteriores actividades de Bunding" (Clarín, 1/8/1976, p.20). Entre los enseres encontraron desde garrafas de gas y cajas de velas hasta siete sábanas blancas. Con respecto a estas, el detenido había declarado que las había sustraído de una casa de Glew pero que no había entrado en ella porque estaban colgadas en la soga, en el patio (Clarín, 1/8/1976, p. 10).

Como puede apreciarse, son casos desopilantes y absurdos. De hecho, a diferencia de otros en los que se realza el accionar heroico de las fuerzas de seguridad, la mención a la "comisión policial" enviada al domicilio de un delincuente de toallas y sábanas blancas, enfatiza el carácter extravagante del hecho. En relación con el accionar del ladrón de cables, que Clarín tematiza como "el colmo de un ladrón" (Clarín, 5/8/1976, p. 22) resulta que la víctima es el mismo ladrón que intentó hacerse de un cable de alta tensión. En el caso de Bunding hay que remarcar que mientras que Clarín lo definía como un malandra de poca monta que hurtaba sábanas blancas, elementos electrónicos, cajas de cigarrillos, sábanas y toallas, Crónica adoptaba un tono más moralista y condenatorio al remarcar que "tenía a mal traer a los vecinos" y que los órganos que robaba tenían un valor superior "a los 80 millones de pesos viejos" (Crónica, 1/8/1976, p. 6)

Retomando la apreciación de Steimberg (2000) sobre que, desde 1980 en adelante, las fronteras discursivas entre prensa seria y amarilla tendieron a borrarse, ya que fue más difícil diferenciar los rasgos textuales de los publicaciones tradicionalmente definidas como amarillas o sensacionalistas de los de aquellas clasificadas como serias, podemos sostener que ambos diarios -aun cuando sus contratos de lectura no son equiparables- construían sus noticias policiales con un lenguaje coloquial, cuyo rasgo distintivo era el sensacionalismo, que está presente desde el origen del género, pero que sin embargo ya en 1976 constituía una modalidad enunciativa utilizada por la prensa de referencia en sus crónicas rojas.

Estos "ladrones de gallinas" o delincuentes de menor peligrosidad que aquí retratamos en la figura de "ladrón de cables" y del "ladrón de sábanas blancas y órganos electrónicos" se asocian a la imagen de criminal manso y re-educable Matías, mantener la expresión con guiones en la misma línea, sin cortar por guion tal como lo caracterizó Fray Mocho hacia 
fines del siglo XIX a la vez que resulta identificable con la underclass esto es, clases desfavorecidas de desempleados o subempleados, marginados de la sociedad ${ }^{40}$.

El marco interpretativo desde el cual se construyen las series informativas aquí analizadas se encuadra en lo que Kessler (2009) presenta como la "teoría del etiquetamiento", que permite "clasificar" como delincuentes a todos aquellos que se aparten de las reglas establecidas como normales por cierto grupo o individuos.

Es desde aquí como las agendas periodísticas sobre el delito y la violencia identifican tres modelos delincuenciales que adquieren espesor en las figuras del "delincuente subversivo", el criminal de "alta peligrosidad" y el "ladrón de gallinas". Cada uno de ellos sintetiza y representa distintos grados de peligros y amenazas para la sociedad y, sobre todo entre 1976-1978, del orden que se busca restablecer. En razón de ello, las narrativas mediáticas habilitaban y legitimaban distintos tipos de reclamos y acciones por parte del Estado.

\section{Conclusiones}

Nos propusimos estudiar las agendas sobre el denominado "delito subversivo" y el "delito común" de la prensa gráfica de circulación nacional en el marco de una compleja etapa de la historia nacional, con la pretensión de comprender cuáles fueron los núcleos argumentativos desarrollados por el periodismo en torno al delito, el orden y el control social. Si bien los casos aquí referenciados se ubican dentro de los primeros cuatro años (1976-1979) de la última dictadura cívico-militar argentina, sirven para ilustrar los modos como los medios de prensa elegidos construyeron las representaciones sobre el crimen a lo largo de 1976-1983, teniendo en cuenta las particularidades y diferencias de cada uno ${ }^{41}$.

En virtud del análisis realizado, identificamos en la superficie redaccional de los diarios analizados la coexistencia de tres modelos delincuenciales -el subversivo, el asesino y el "ladrón de gallinas" - y la emergencia de dos narrativas antagónicas pero complementarias sobre los métodos represivos y de control social utilizados durante el período.

A partir de los casos escogidos, sostenemos que la narración del delito adquiere modalidades discursivas específicas para informar sobre los "delitos subversivos" o los "delitos comunes".

\footnotetext{
40 Es de suma importancia aclarar que la teoría de la underclass sería retomada en los 80 por ideólogos neoconservadores que le imprimirían un carácter racial. Nosotros tomamos la concepción de Myrdal que repone Kessler (2009).

${ }^{41}$ El período 1976-1983 es cambiante en cuanto al comportamiento de la prensa en relación con la violencia y el orden. Si bien en 1976 se utilizaban términos propios del género policial para explicar la "lucha antisubversiva", hacia 1982 la clave interpretativa para la cobertura de delitos comunes anclaba en explicaciones que se basaban en "el retorno del terror" -en alusión a las prácticas represivas desplegadas desde el Estado para acabar con la "subversión". Sin embargo, los modelos delincuenciales y las narrativas mediáticas en torno al delito que analizamos en este trabajo se mantuvieron durante todo el período.
} 
En primer lugar, en las "crónicas rojas" el cronista es omnisciente, genera suspenso, dramatiza, enfatiza el aspecto absurdo de algunos delitos y lo hace con actitudes, gestos y lenguajes coloquiales. Las noticias sobre "la subversión", en tanto, son espacio para la reproducción textual de los comunicados oficiales, y borran las marcas enunciativas que permiten identificar al cronista.

En segundo lugar, si bien cuando se informaban sobre atentados, como el que analizamos aquí, la subversión adquiría rostro y permitía mostrar cómo actuaba la subversión y cuáles eran sus motivaciones psicológicas, en las series informativas sobre la "lucha antisubversiva", que los medios tematizaban como enfrentamientos, se utilizaban formas impersonales y la voz pasiva, borrando de este modo al sujeto de la acción (persona, número, modo o tiempo) y enfatizando la acción ${ }^{42}$. Tal como sostiene Van Dijk $(1997,63)$ los actores con poder como las autoridades, en este caso las fuerzas de seguridad, tienden a aparecer como primer sujeto cuando realizan una acción neutral o positiva, mientras que se los sitúa en una construcción pasiva o implícita como agentes de acciones negativas. También era recurrente la utilización de la cuantificación -esto es la explicitación del número de los muertos- en los modos de titular, lo cual resaltaba la importancia de la exactitud de los dichos. La combinación de aserciones $y$ de cuantificaciones, en un discurso en el que ni el enunciador ni el destinatario están explícitamente marcados, designa un contrato en el que un enunciador objetivo e impersonal habla la verdad (Verón, 1985). A su vez, la figura del "subversivo" y del "extremista" tal como lo había planteado el discurso militar, en términos de "enemigos internos", al ser recogido por los medios ya hacia fines de los 60 (Casabona, 2013) logró imponer un relato respecto de estos colectivos políticos en el que se los había caracterizado exitosamente como los adversarios de la totalidad de "lo nacional". Por este motivo, el ideologema ${ }^{43}$ "enemigos internos", subyacente en esos discursos, junto con la apelación a una retórica del género policial, fue funcional no solo para sustraer de la discusión política a la "cuestión subversiva" sino también para reclamar y justificar el exterminio desde el aparato represivo estatal de la "subversión política", mediante reagrupaciones y formulaciones antinómicas del tipo "orden versus caos", "subversión versus Nación". Aun con contratos de lectura o líneas editoriales diferenciables (Clarín, vinculado al desarrollismo y Crónica, cercano al peronismo pero no a Montoneros), y de su mayor o menor acompañamiento al gobierno militar, todos los medios coincidieron en relación con lo que se consideraba noticiable como así también en la caracterización de los temas, personajes y tipos de acontecimientos.

\footnotetext{
42 Por ejemplo: “Abatieron a 21 extremistas en varios tiroteos" (Clarín, 11/9/1976); “Abatieron a 9 extremistas” (Crónica, 3/8/1976).

43 Tal como lo plantea Angenot (2010) los ideologemas son pequeñas unidades significantes dotadas de aceptabilidad difusa en una doxa dada.
} 
La construcción de las agendas temáticas y atributivas se basó en la selección y jerarquización de asuntos con arreglo a criterios de noticiabilidad que se establecen de acuerdo con la gravedad y cercanía de los acontecimientos pero también con la censura y la persecución que caracterizó al período.

Durante el proceso de investigación, confirmamos la relevancia que los medios analizados otorgaron a la llamada delincuencia subversiva, a través de la tematización y la atribución, y planteamos su vinculación con la coyuntura sociopolítica y económica en la que los diarios estaban inmersos y de la cual algunos se beneficiaron con mayor notoriedad que otros.

A su vez, si bien las medidas de disciplinamiento en los órdenes políticos, económicos y culturales se aplican con intensidad durante el período hallan su punto más alto entre 1976-1978 (Varela, 2001) momento en el que los medios de prensa ubican en el centro de su oferta informativa a las "noticias sobre la subversión", que abarcaban desde las operaciones de los grupos de tareas encargados de "exterminar el peligro subversivo" presentados como "enfrentamiento entre sediciosos y fuerzas de seguridad", hasta los crímenes cometidos por los "sediciosos" como, por ejemplo, el atentado a Lambruschini o a las fuerzas policiales como así también la "muerte dudosa" de empresarios como Graiver ${ }^{44} \mathrm{o}$ el secuestro de empresarios.

$\mathrm{Al}$ ser la información publicada en esa agenda tomada exclusivamente de las fuentes oficiales, los asesinatos cometidos por las propias fuerzas de seguridad se endilgaban a las organizaciones político-armadas (tal fue el caso de los curas palotinos, del cual se responsabilizó a Montoneros). En estas coberturas remarcaban el accionar delictivo premeditado y racional del "elemento subversivo".

Es interesante notar que, pese a su carácter masivo, la clandestinidad de la represión le permitió al gobierno negar su existencia durante los primeros años, mientras que la oferta informativa de la prensa la "ocultaba mostrando"45 (Bourdieu, 1997) bajo la construcción de una agenda del "delito subversivo". Es decir, con la utilización de una retórica de tipo delictivo se otorgaba visibilidad a series noticiosas que reducían a un "mero enfrentamiento" el despliegue de la maquinaria estatal represiva y clandestina (con lo cual además se equiparaba el accionar estatal con el de las agrupaciones políticas opositoras, dando lugar a la idea de "guerra") y se construía una imagen del "subversivo" a partir de la utilización de términos propios del género policial: "delincuentes",

\footnotetext{
${ }_{44}$ Este tipo de casos les permitía a los medios enfatizar el "componente internacional" y el aparato de financiamiento de la subversión.

45 Bourdieu utiliza la expresión "ocultar mostrando" para referirse a los modos del decir televisivo y lo recuperamos aquí porque nos permite ilustrar, explicar y comprender el comportamiento enunciativo de los diarios analizados durante el período. De acuerdo con el autor la TV ("oculta mostrando") cuando "muestra algo distinto de lo que tendría que mostrar (...) y también cuando muestra lo que debe, pero de tal forma que hace que pase inadvertido o que parezca insignificante o lo elabora de tal modo que toma un sentido que no corresponde en absoluto a la realidad" (Bourdieu, 1997, 24).
} 
"asesinos", “autores de atentados", “detenidos"46. Martini (2007) sostiene que hacia 1976 los medios retoman la táctica editorial con la que históricamente suelen "calificar las acciones de quienes son puestos al margen de la legalidad política durante gobiernos de facto, y recuerda la criminalización legal impuesta al derecho de huelga que establece nuestra primera Constitución de 1853" (p. 5). Durante el período inmediatamente anterior a 1976, el discurso de los medios sobre el "aniquilamiento" de los elementos "subversivos" eran similares ${ }^{47}$, por lo tanto, se puede inferir que demandaban métodos represivos de control social, independientemente de su supuesta legalidad o ilegalidad y de la existencia o no de Estado de Derecho.

Es desde este esquema interpretativo propuesto por las series informativas de la agenda sobre el "crimen subversivo" en el que se advierte la configuración e instalación de una narrativa autoritaria y represiva que demandaba específicamente mayor control social y el restablecimiento de un orden perdido, justificando la violencia desmedida del Estado y un control social absoluto. Si bien el delito es una categoría flexible, y sus modos de narración adquieren particularidades específicas en cada período histórico (Ludmer, 1999), estamos en condiciones de afirmar que las series informativas que instalan determinadas modalidades delictivas habilitan modos de reclamos por parte de la prensa, ya sea para demandar castigos ejemplares ya sea para modificar o sancionar nuevas leyes.

Esta narrativa se advierte en las crónicas policiales que relatan los casos de delincuentes de mayor peligrosidad como las envenenadoras. De todos modos, es pertinente destacar que si bien se legalizó la pena de muerte -introducida el 25 de junio de 1976 en el Código Penal- nunca fue utilizada como condena formal durante la dictadura (Groisman, 2001; Vázquez, 1985).

Además, se configuró una narrativa de carácter "correctivo"/tolerante, pero no por eso dejaba de ser punitiva y estigmatizadora, que veía al delincuente común como un "inadaptado social" que, probablemente carente de "contención familiar" como asimismo

\footnotetext{
46 Schindel (2012) estudia las operaciones sociales que, apoyadas en la rutinización del periodismo, tejieron una trama de indiferencia en torno a las víctimas e introdujeron la figura espectral de la desaparición. En este sentido se detiene en el análisis de la utilización obstinada y obsesiva que hacen las noticias del término "abatir", siempre asociado a "subversivos", en las numerosas noticias de supuestos "enfrentamientos" como si "abatir", señala, "fuera idéntico a matar". Según su descripción: "Las acepciones que asigna el diccionario al verbo abatir son derribar, derrocar, echar por tierra (...) Si bien es un verbo transitivo, en la mayor parte de las acepciones no se aplica a personas sino más bien a cosas. María Moliner agrega que asociado a 'soberbia, orgullo' o palabras semejantes significa humillar y finalmente, con 'a' o 'ante': 'cesar en una actitud de ataque o de resistencia, ceder, doblegarse, rendirse'. Esta última acepción es la única que podría aplicarse con coherencia al relato de los 'enfrentamientos': podría decirse que quienes son 'abatidos', cesan en la actitud de ataque o resistencia, tal como enfatizan los comunicados. Allí el verbo denota una actitud de obligar a deponer las armas o la actitud de combate, pero en ningún caso 'matar'". Entonces, agrega, “¿Qué significa entonces abatir? Y, sobre todo, quien ha sido abatido ¿está vivo o muerto?” (Schindel, 2012, p. 165-166).

47 Aunque se ocupe del posicionamiento que el diario Clarín adoptó hacia el final del gobierno de Isabel Martínez de Perón, se recomienda la lectura de Borrelli (2008b), porque provee datos que ratifican esta forma de informar sobre la guerrilla adoptada por los medios en el período previo a la dictadura, y el trabajo de Díaz (2002), que se cierne sobre el consenso que los diarios le otorgaron al golpe de Estado de 1976.
} 
de recursos económicos y educativos, delinquía para sobrevivir. Por tanto, si bien era punible por ubicarse al "margen de la ley" debía ser reeducado y reinsertado socialmente.

Estas lógicas confrontadas pero suplementarias las interpretamos como una reactualización de la justicia retributiva, cuya lógica es la "del ojo por ojo y diente por diente": la norma debe imponer un castigo que se identifique con el crimen cometido, y obtenerse la reciprocidad.

Esta breve recapitulación intentó dar mayor volumen a los puntos salientes del presente trabajo que nos permitieron estudiar y comprender los mecanismos de tratamiento informativo en vinculación con el fenómeno de la violencia, el orden y el control social en un contexto signado por la censura, la autocensura, el disciplinamiento y la persecución.

Finalmente, a partir de los hallazgos encontrados se puede afirmar que los núcleos argumentativos que se configuraron en los medios de prensa durante el período 19761979 en torno a la violencia, el orden y el control social, basados en una lógica represiva de corte autoritario que sirve para fundamentar y legitimar el pedido de "mano dura" siguen vigentes, aunque con variaciones, en los relatos sobre la llamada inseguridad y en episodios de protesta social recientes (Artese y Gielis, 2014). Pero eso es objeto de otro trabajo.

\section{Referencias}

Acuña, C. y Smulovitz, C. (1995). "Militares en la transición argentina: del gobierno a la subordinación constitucional". En Acuña, C. et al. Juicio, castigos y memorias. Derechos humanos y justicia en la política argentina (pp. 19-99). Buenos Aires: Nueva Visión.

Angenot, M. (2010). "El discurso social: problemática de conjunto". En Los discursos sociales. Los límites históricos de lo pensable y lo decible (pp. 21-49). Buenos Aires: Siglo XXI Editores.

Artese, M. y Gielis, L. (2014). La protesta durante el primer kirchnerismo (2003-2004): hechos y declaraciones según los diarios La Nación y Clarín. Estudios, Centro de Estudios Avanzados, Universidad Nacional de Córdoba, 32. Recuperado de https:// revistas.unc.edu.ar/index.php/restudios/article/view/11584.

Artese, M. y Roffinelli, G. (2007). Responsabilidad civil y genocidio: acciones y declaraciones públicas durante el Operativo Independencia. Buenos Aires: Tientos Editora. Recuperado de http://bibliotecavirtual.clacso.org.ar/Argentina/iigguba/20110610042027/respcivil_gen ocidio.pdf

Avellaneda, A. (1986). Censura, autoritarismo y cultura: Argentina 1960-1983/1. Buenos Aires: Centro Editor de América Latina.

Blaustein, E. y Zubieta, M. (1999). Decíamos Ayer. La prensa argentina bajo el proceso. Buenos Aires: Colihue. 
Borrat, H. (1989). El periódico, actor político. Barcelona: Gustavo Gili.

Borrelli, M. (2008a). El diario de Massera. Historia y política editorial de Convicción: "la prensa del proceso". Buenos Aires: Koyatun.

Borrelli, M. (2008b). Hacia el "final inevitable". El diario Clarín y la "caída" del gobierno de Isabel Perón (1975-1976). (Tesis de maestría en Comunicación y Cultura). Facultad de Ciencias Sociales, Universidad de Buenos Aires (mimeo).

Borrelli, M. (2011). Una "batalla ganada": Clarín y la compra de Papel Prensa (19761978). En Saborido, J. y Borrelli, M. (Comp.), Voces y silencios: la prensa argentina y la dictadura militar (1976-1983) (pp. 19-53). Buenos Aires: Eudeba.

Borrelli, M. (2016). Por una dictadura desarrollista. Clarín frente a los años de Videla y Martínez de Hoz (1976-1981). Buenos Aires: Biblos.

Bourdieu, P. (1997). Sobre la televisión. Barcelona: Anagrama.

Brunetti, P. M. (2011). "Crónica roja y sensacionalismo: maneras de hacer, maneras de Ver”. En Revista Oficios Terrestres, 1(26), 1-17. Recuperado de http://perio.unlp. edu.ar/ojs/index.php/oficiosterrestres/article/view/657.

Caimari, L. (Comp) (2007). La ley de los profanos. Delito, justicia y cultura en Buenos Aires (1870-1940). Buenos Aires: Fondo de Cultura Económica.

Caimari, L. (2012). Mientras la ciudad duerme. Pistoleros, policías y periodistas en Buenos Aires, 1920-1945. Buenos Aires: Siglo XXI Editores.

Canelo, P. (2009). El proceso en su laberinto. La interna militar de Videla a Bignone. Buenos Aires: Prometeo.

Canelo, P. (2016). La política secreta de la última dictadura argentina (1976-1983). Buenos Aires: Edhasa.

Canitrot, A. (1980). La disciplina como objetivo de la política económica. Un ensayo sobre el programa económico del gobierno argentino desde 1976. Desarrollo Económico. 19(76), 453-475. doi: https://doi.org/10.2307/3466561.

Casabona, G. L. (2013). Clarín y La Nación en la construcción de representaciones sobre el "enemigo interno" en tiempos de autoritarismo, violencia y represión (1969). Trabajo presentado en VII Jornadas de Jóvenes Investigadores, del Instituto de Investigaciones Gino Germani, Buenos Aires.

Casola, N. (2015). La militancia del PCA durante la última dictadura en Argentina. Un análisis sobre la producción, circulación y recepción de la línea partidaria. Aletheia, 5(10). Recuperado de http://www.aletheia.fahce.unlp.edu.ar/numeros/ numero-10/pdfs/Casola-\%20Ok.pdf, 1-16.

Cavarozzi, M. (2006). Autoritarismo y democracia (1955-2006). Buenos Aires: Ariel.

De Riz, L. (1986). Retorno y derrumbe. El último gobierno peronista. Buenos Aires: Hyspamerica.

Díaz, C. L. (2002). La cuenta regresiva. Buenos Aires: La Crujía. 
Díaz, C. L., Giménez, M. y Passaro, M. M (2004). Cuando ni los “objetivos” ni los “plazos" respetaron la libertad de expresión. La legislación entre 1976-1981. Anuario de investigaciones 2003, La Plata: Facultad de Periodismo y Comunicación Social, Universidad Nacional de La Plata, 116-126.

Díaz, C. L. y Passaro, M. M. (2009). "Papel prensa y la dictadura. Una historia de silencios, alianzas y oposiciones". En Verano, A. (Ed.). Medios de comunicación en la Argentina: diagnóstico y prospectiva (pp. 139-163), La Plata: Facultad de Periodismo y Comunicación Social, Universidad Nacional de La Plata.

Díaz Noci, J. (1995). Manual de redacción periodística: géneros informativos. Bilbao: Universidad del País Vasco.

Fray Mocho (José S. Álvarez) (2003). Memorias de un vigilante ( $1^{\circ}$ parte). Biblioteca Virtual Universal. Recuperado de http://www.biblioteca.org.ar/libros/88756.pdf.

Ford, A. y Longo Elía, F. (1999). "La exasperación del caso. Algunos problemas que plantea el creciente proceso de narrativización de la información de interés público". En Ford, A.: La marca de la bestia. Identificaciones, desigualdades e infoentretenimiento en la sociedad contemporánea (pp. 245-288), Buenos Aires: Norma.

Ford, A., Martini, S. y Mazziotti, N. (1996). Construcciones de la información en la prensa argentina sobre el tratado del Mercosur. En García Canclini, N. (Coord.). Culturas en globalización (pp. 177-214), Caracas: Nueva Sociedad/CNCA/ CLACSO.

Foucault, M. (1985). Vigilar y castigar. México: Siglo XXI.

Gago, M. P. (2015). Una historia de subversivos, asesinos y ladrones de gallinas. La noticia policial en la prensa gráfica de circulación nacional durante la última dictadura cívico militar en Argentina (1976-1983). (Tesis de doctorado en Ciencias Sociales). Facultad de Ciencias Sociales, Universidad de Buenos Aires (mimeo).

García, H. R. (1997). Cien veces me quisieron matar. Buenos Aires: Planeta.

Garland, D. (2005). La cultura del control. Crimen y orden social en la sociedad contemporánea. Barcelona: Gedisa.

Gasparini, J. (2007). David Graiver. El banquero de los Montoneros. Buenos Aires: Norma.

Gociol, J. e Invernizzi, H. (2002). Un golpe a los libros. Buenos Aires: Eudeba.

Groisman, E. (2001). Utilización del derecho en la dictadura de la junta militar. Espacios de crítica y producción, 27/28. Recuperado de https://es.scribd.com/ document/327117881/Groisman-E-Utilizacion-Del-Derecho-en-La-UltimaDictadura-Militar, 10-19.

Izaguirre, I. et al. (2009). Lucha de clases, guerra civil y genocidio en la Argentina. 19731983. Antecedentes. Desarrollo. Complicidades. Buenos Aires: Eudeba. 
Kessler, G. (2004). Anexo. Las teorías sobre el delito. En Kessler, G. Sociología del delito amateur (pp. 267-292), Buenos Aires: Paidós.

Llonto, P. (2003). La noble Ernestina. El misterio de la mujer más rica del país. Buenos Aires: Astralib.

Lorenz, F. G. (2017). Cenizas que te rodearon al caer. Vidas y muertes de Ana María González, la montonera que mató al Jefe de Policía Federal. Buenos Aires: Sudamericana.

Ludmer, J. (1999). El cuerpo del delito. Un manual. Buenos Aires: Perfil.

Mangone, C. (1996). Dictadura, cultura y medios. Causas y Azares, 4, 39-46.

Marín, J. C. (1996). Los hechos armados. Argentina 1973-1976. La acumulación primitiva del genocidio. Buenos Aires: Ediciones P.I.CA.SO./La Rosa Blindada.

Marroquín Parducci, A. (2007). Indiferencias y espanto. Relatos de jóvenes y pandillas en la prensa escrita de Guatemala, El Salvador y Honduras. En Rey, G. (Coord.). Los relatos periodísticos del crimen. Cómo se cuenta el delito en la prensa Latinoamericana (pp. 55-91), Bogotá: Centro de Competencia en Comunicación Friedrich Ebert Stiftung.

Martini, S. (2000). Periodismo, noticia y noticiabilidad. Buenos Aires: Norma.

Martini, S. (2007). La prensa gráfica argentina: reflexiones sobre la calidad periodística, la información "socialmente necesaria" y la participación ciudadana en las agendas sobre el delito. En Foro de Periodismo Argentino (Ed.), Periodismo de calidad: debates y desafíos (s/d), Buenos Aires, La Crujía. Recuperado de https:// criminologiacomunicacionymedios.files.wordpress.com/2013/08/agendas-sobreel-delito-martini.pdf.

Martini, S. y Gobbi, J. (1998). “Agendas públicas y agendas periodísticas”. Documento de la cátedra de Comunicación II. Carrera de Ciencias de la Comunicación. Buenos Aires: Facultad de Ciencias Sociales, Universidad de Buenos Aires.

Martini, S. y Luchessi, L. (2004). Los que hacen la noticia. Periodismo, información y poder. Buenos Aires: Biblos.

Martini, S. y Pereyra, M. (Ed). (2009). La irrupción del delito en la vida cotidiana. Buenos Aires: Biblos.

Mestman, M. (1992). Estado y sistema de medios en Argentina 1966-1976. Buenos Aires: Carrera de Ciencias de la Comunicación, Facultad de Ciencias Sociales, Universidad de Buenos Aires (mimeo).

Mochkofsky, G. (2004). Timerman. El periodista que quiso ser parte del poder (19231999). Buenos Aires: De Bolsillo.

Muraro, H. (1987). La comunicación masiva durante la dictadura militar y la transición democrática en la Argentina 1973-1986. En Landi, O. (Comp). Medios, transformación cultural y política (pp. 15-45), Buenos Aires: Legasa. 
Novaro, M. y Palermo, V. (2003). La Dictadura Militar 1976/1983. Buenos Aires: Paidós. Oliveira, A. y Tiscornia, S. (1997). Estructura y práctica de las policías en la Argentina. Las redes de ilegalidad. Documentos de Trabajo. Buenos Aires: Centro de Estudios Legales y Sociales. Recuperado de http://www.cels.org.ar/common/documentos/ control_democratico2.pdf.

Paz, M. L. (2003). Movimiento de sacerdotes para el tercer mundo, la otra iglesia (República Argentina 1967-1976). (Trabajo final de grado). Universidad Nacional de La Plata. Facultad de Humanidades y Ciencias de la Educación. Recuperado de http://www.memoria.fahce.unlp.edu.ar/tesis/te.571/te.571.pdf.

Pereyra, M. (2013). Política, discurso y prensa popular: la figura del "enemigo interno" (1916-1930; 1943-1946 y 1969). Trabajo presentado en Jornadas de la Carrera de Ciencias de la Comunicación "Comunicación y Ciencias Sociales. Legados, diálogos, tensiones y desafíos", de la Facultad de Ciencias Sociales, Universidad de Buenos Aires, Buenos Aires.

Postolski, G. y Marino, S. (2006). Relaciones peligrosas: los medios y la dictadura entre el control, la censura y los negocios. Revista de Economía Política de las Tecnologías de la Información y Comunicación, 8(21), Recuperado de http://seer.ufs.br/index. php/eptic/article/viewFile/299/286,

Rússovich, R. M. B. de, y Lacroix, M. L. (1986). “Los grandes diarios”. En Mendelevich, P. et al. Crónicas del periodismo. Buenos Aires: Centro Editor de América Latina, Col. Cuadernos de Historia Popular Argentina, 11.

Ruiz, A. y Albertini, E. (2008). Fuentes Periodísticas: concepto, clasificación y modos de uso. En Tram(p)as de la Comunicación y la Cultura, 60, La Plata, Facultad de Periodismo y Comunicación Social, Universidad Nacional de la Plata,14-25.

Saborido, J. y Borrelli, M. (Coord.) (2011). Voces y Silencios: prensa y política durante la dictadura militar (1976-1983). Buenos Aires: Eudeba.

Saítta, S. (1998). Regueros de tinta. El diario Crítica en la década de 1920. Buenos Aires: Sudamericana.

Schindel, E. (2012). La desaparición a diario. Sociedad, prensa y dictadura (1975-1978). Villa María: Eduvim.

Sidicaro, R. (1996). El régimen autoritario de 1976: refundación frustrada y contrarrevolución exitosa. En Quiroga, H. y Tcach, C. (Comp). A veinte años del golpe. Con memoria democrática (pp. 9-26), Rosario: Homo Sapiens.

Sivak, M. (2013). Clarín, el gran diario argentino. Una historia. Buenos Aires: Planeta. Sivak, M. (2015). Clarín. La era Magnetto. Buenos Aires: Planeta.

Steimberg, O. (1987). Prensa amarilla/prensa blanca: notas sobre una conocida y no definida oposición de géneros. En Rivera, J. y Romano, E., Claves del periodismo argentino actual (pp. 149-159), Buenos Aires: Tarso. 
Steimberg, O. (2000). Naturaleza y cultura en el ocaso (triunfal) del periodismo amarillo. CIC Cuadernos de Información y Comunicación, 5, Madrid: Universidad Complutense de Madrid, 235-240.

Ulanovsky, C. (2005). Paren las rotativas. Diarios, revistas y periodistas. Tomos I y II. Buenos Aires: Emecé.

Van Dijk, T. A. (1990). La noticia como discurso. Comprensión, estructura y producción de la información. Buenos Aires: Paidós.

Van Dijk, T. A. (1997). Racismo y análisis crítico de los medios. Barcelona: Paidós.

Varela, M. (2001). Los Medios de Comunicación durante la Dictadura: Silencio, Mordaza y "Optimismo". Revista Todo es Historia, Buenos Aires, 404, 50-63.

Vázquez, E. (1985). La última. Origen, apogeo y caída de la dictadura militar. Buenos Aires: Eudeba.

Verón,E.(1985).El análisis del “Contrato de Lectura”, un nuevo método para los estudios de posicionamiento de los soportes de los media. Les Medias: Experiences, recherches actuelles, aplications, París: Institut de Recherches et d'Etudes Publicitaires.

Vezzetti, H. (2002). Pasado y presente. Guerra, dictadura y sociedad en la Argentina. Buenos Aires: Siglo XXI Editores.

Vitale, A. (2015). ¿Cómo pudo suceder? Prensa escrita y golpismo en la Argentina (19301976). Buenos Aires: Eudeba.

Voloshinov, V. (1976). Marxismo y filosofía del lenguaje. Buenos Aires: Editorial Nueva Visión.

Wolf, M. (1991). La investigación de la comunicación de masas. Críticas y perspectivas. Barcelona: Paidós.

Yannuzzi, M. A. (1996). Política y dictadura. Rosario: Fundación Ross. 